\title{
Experimental and theoretical evidence for the load sequence effect in the compressive fatigue behavior of concrete
}

\author{
Abedulgader Baktheer $($ iD $\cdot$ Rostislav Chudoba $(i)$
}

Received: 5 September 2020/ Accepted: 20 February 2021/Published online: 29 March 2021

(C) The Author(s) 2021

\begin{abstract}
A realistic prediction of the concrete fatigue life exposed to high-cycle loading scenarios with variable amplitudes is of utmost importance for a reliable and economically efficient design of civil engineering infrastructure for transport and energy supply. Current design codes estimate the fatigue life under variable amplitudes using the Palmgren-Miner rule, which assumes a linear scaling between lifetimes measured for uniform cyclic loading scenarios. Several experimental series conducted in the past, however, indicate that this assumption is not valid and that it may lead to unsafe design. In this paper, an experimental and theoretical investigations of the fatigue loading sequence effect in normal- and highstrength concrete behavior are presented, which confirm this observation. In particular, a test campaign with 135 cylinder specimens, including three concrete grades and six different loading scenarios has been conducted. Several response characteristics of the fatigue behavior including Wöhler curves, fatigue creep curves and evolving shapes of hysteretic loops have been evaluated. To substantiate the experimental results, a theoretical explanation of the observed
\end{abstract}

\footnotetext{
A. Baktheer $(\square) \cdot$ R. Chudoba

Institute of Structural Concrete, RWTH Aachen

University, Mies-van-der-Rohe-Straße 1, 52074 Aachen,

Germany

e-mail: abaktheer@imb.rwth-aachen.de

R. Chudoba

e-mail: rostislav.chudoba@rwth-aachen.de
}

sequence effect is formulated based on the assumption, that energy is dissipated uniformly within the volume of a test specimen during subcritical, compressive cyclic loading. Then, superposition of energy dissipation profiles along the lifetime measured for constant amplitudes becomes possible and a theoretical justification of the experimentally observed sequence effect can be provided. Moreover, a reverse sequence effect reported in the literature for bending fatigue of concrete can then be explained by an unevenly distributed energy dissipation over a cracked specimen. Supported by the theoretical consideration, the processed experimental data is used to validate existing fatigue life assessment rules by testing their ability to reflect the load sequence effect.

Keywords Concrete Fatigue - Cyclic loading · Loading sequence effect · Variable amplitudes . Damage $\cdot$ High-strength concrete $\cdot$ Energy dissipation

\section{List of symbols}

$\eta \quad$ Cumulative consumed fatigue life

$N_{i} \quad$ Number of loading cycles of the range $i$

$N_{i}^{\mathrm{f}} \quad$ The number of cycles to failure under a constant amplitude of the range $i$

$n \quad$ Number of loading ranges

$\Delta \eta_{i} \quad$ Correction term of the P-M rule

$S^{\max } \quad$ The upper level of the loading range

$S^{\text {min }} \quad$ The lower level of the loading range

$f_{\mathrm{c}} \quad$ Compressive strength of the concrete 
$\omega \quad$ Damage paramete

$a, b, c \quad$ Constants for the cumulative damage rule by Shah

$\Delta S^{\max } \quad$ Upper jump between two loading ranges

$\Delta S^{\min } \quad$ Lower jump between two loading ranges

$\mathcal{R}() \quad$ Response surface of parameters

$\overline{S_{i}} \quad$ Mean loading level within two loading ranges

$\tilde{\eta}_{i} \quad$ Cumulative consumed fatigue life prior to the loading jump

$S_{i}^{\mathrm{m}} \quad$ Mean value of individual loading range

$\eta_{\mathrm{x}} \quad x$ Coordinate of the response surface knee point

$\Delta \eta_{\max } \quad y$ Coordinate of the response surface knee

$A, B, C$ Material parameters of the enhanced $\mathrm{P}-\mathrm{M}$ rule

$\eta_{\uparrow} \quad$ Jump up material parameter of the enhanced $\mathrm{P}-\mathrm{M}$ rule

$\eta_{\downarrow} \quad$ Jump down material parameter of the enhanced $\mathrm{P}-\mathrm{M}$ rule

$\beta_{\uparrow} \quad$ Jump up material parameter of the enhanced $\mathrm{P}-\mathrm{M}$ rule

$\beta_{\downarrow} \quad$ Jump down material parameter of the enhanced $\mathrm{P}-\mathrm{M}$ rule

$\eta_{\text {rem }} \quad$ Remaining fatigue life predicted by enhanced $\mathrm{P}-\mathrm{M}$ rule

$\mathcal{G} \quad$ Energy dissipation during fatigue life

$\mathcal{G}_{\mathrm{H}} \quad$ Energy dissipation during during (H) scenario

$\mathcal{G}_{\mathrm{L}} \quad$ Energy dissipation during during

(L) scenario

$\mathcal{G}_{\text {jump }} \quad$ Energy dissipation during the switch from (L) to $(\mathrm{H})$ load level

$\eta_{\mathrm{H}} \quad$ Consumed fatigue life during (H) scenario

$\eta_{\mathrm{L}} \quad$ Consumed fatigue life during (L) scenario

$\eta_{\mathrm{H}-\mathrm{L}} \quad$ Consumed fatigue life during (H-L) scenario

$\eta_{\mathrm{H}-\mathrm{L}} \quad$ Consumed fatigue life during $(\mathrm{H}-\mathrm{L})$ scenario

$\eta_{\mathrm{L}-\mathrm{H}} \quad$ Consumed fatigue life during $(\mathrm{L}-\mathrm{H})$ scenario

$\eta_{\mathrm{H}-\mathrm{L}}^{\star} \quad$ Residual fatigue life for the (L) scenario after consuming a certain amount of fatigue life with $(\mathrm{H})$ scenario

$\boldsymbol{x} \quad$ Field variable representing the volume of the tested specimen

$\boldsymbol{S}(\boldsymbol{x}) \quad$ Distribution of inelastic state changes within the volume of the test specimen
$S_{\mathrm{H}}(\boldsymbol{x}) \quad$ Distribution of inelastic state changes within the volume of the test specimen during $(\mathrm{H})$ scenario

$S_{\mathrm{L}}(\boldsymbol{x}) \quad$ Distribution of inelastic state changes within the volume of the test specimen during (L) scenario

\section{Introduction}

The fatigue behavior of concrete has been usually investigated experimentally for loading scenarios with constant amplitudes. Fatigue life of a particular material is typically characterized by the Wöhler/ S$\mathrm{N}$ diagrams. However, in reality the concrete components and structures are subjected to loading scenarios with variable amplitudes [1, 2]. For example, highway and railroad bridges are exposed to millions of lowamplitude loading cycles that are combined with accidental high stress levels and occasional overloads [3-5]. Onshore and offshore structures, such as the wind turbine towers made of concrete, are exposed to stochastic wind action and wave oscillations that can be idealized as a loading scenario with variable amplitudes [6, 7]. Another example of a non-uniform cyclic loading scenario is the seismic action, that can be represented as a multilevel loading consisting of several cyclic blocks with constant or increasing amplitudes [8-10]. These examples document the importance for detailed analysis of the load sequence effect as basis for both an economic and reliable design of concrete structures exposed to fatigue loading [11].

Since the experimentally obtained Wöhler curves only characterize uniform fatigue loading, refined methods of the fatigue damage assessment for loading scenarios with variable amplitudes are needed. In the current design codes e.g. [12-15], the widely used Palmgren-Miner P-M [16, 17] rule is considered. This rule assumes that the overall fatigue life for a loading scenario consisting of $n$ number of different load ranges can be predicted by a linear interpolation of the fatigue life for each load range separately. The fatigue failure is assumed to occur when

$$
\eta=\sum_{i=1}^{n} \frac{N_{i}}{N_{i}^{\mathrm{f}}}=1,
$$


where $N_{i}^{\mathrm{f}}$ is the number of cycles to failure achieved under a constant amplitude loading corresponding to the level $i$ and $N_{i}$ is number of applied cycles at the load level $i$ during a multi-level loading scenario.

As can be seen from the formula, this hypothesis assumes a linear scaling between the lifetime proportions corresponding to the load ranges performed. Since the order in which the loading ranges are applied is immaterial, the sequence effect cannot be taken into account.

In spite of the fact that the loading sequence effect is highly relevant for any structure subjected to fatigue loading, only a little amount of experimental research studying the loading sequence effect of concrete fatigue behavior has been reported in the literature so far. An Experimental program performed by Holmen [18] was using the loading scenario consists of two cycling loading ranges i.e. high $(\mathrm{H})$, and low (L) with different sequences $(\mathrm{H}-\mathrm{L}$, and $\mathrm{L}-\mathrm{H})$. The obtained results have been compared with the concept of the $\mathrm{P}-\mathrm{M}$ rule. Apparently, the failure for the $(\mathrm{H}-\mathrm{L})$ scenario was observed significantly earlier than predicted by the $\mathrm{P}-\mathrm{M}$ rule. The experimental results presented by Petkovic et al. [19] show that the P-M rule delivers a conservative fatigue life prediction of the specimens tested with the $(\mathrm{L}-\mathrm{H})$ scenario. Another experimental program presented by Bennett [20] including both the $(\mathrm{H}-\mathrm{L})$ and $(\mathrm{L}-\mathrm{H})$ loading scenarios, shows that the consumed fatigue life according to $\mathrm{P}-\mathrm{M}$ rule $\eta$ for the $(\mathrm{H}-\mathrm{L})$ scenario is always less than the consumed fatigue life of the $(\mathrm{L}-\mathrm{H})$ scenario. The experimental results presented by Tepfers et al. [6], and Klausen [21] indicate a dependency of the fatigue behavior on the changed order of loading ranges, but due to the large scatter of the results clear tendency for the $(\mathrm{L}-\mathrm{H})$ and $(\mathrm{H}-\mathrm{L})$ sequences cannot be concluded $[22,23]$. These studies of the loading sequence effect for compressive fatigue loading [6, 18-21] suggest the conclusion in relation to the $\mathrm{P}-\mathrm{M}$ rule, $(\mathrm{H}-\mathrm{L})$ scenario leads to the fatigue life reduction while the $(\mathrm{L}-\mathrm{H})$ sequence results in an extension.

On the other hand, the few experimental results for concrete fatigue in tension published by Hilsdorf [24] show a reverse behavior i.e. the $(\mathrm{L}-\mathrm{H})$ and $(\mathrm{H}-\mathrm{L})$ scenarios deliver a reduced and extended fatigue life $\eta$, respectively. Similar results have been obtained numerically for the bond fatigue behavior between concrete and steel reinforcement [25, 26]. The inversion of the sequence effect for different stress configurations demonstrates the high complexity of the problem behind the fatigue sequence effect. Moreover, high costs of long lasting experimental investigations are the reason why only a limited amount of experimental data is available, and, why a sound basis for the definition of both safe and economic engineering design rules for concrete structures exposed to fatigue loading is still missing.

For homogeneous materials, like steel, several nonlinear fatigue damage accumulation rules for varying loading ranges exist [27-32] as alternatives to the $\mathrm{P}-\mathrm{M}$ rule. Only a few fatigue damage accumulation rules, however, have been proposed for concrete behavior exposed to compressive fatigue, e.g. the rule proposed by Shah [33], and the rule suggested by Grzybowski and Meyer [34]. However these empirically based rules show only a limited range of validity as documented in [35]. Nonlinear damage accumulation rules for concrete fatigue behavior under tensile stresses can be found also in [36-38].

Due to the high complexity of the dissipative mechanisms governing the fatigue sequence effect a purely experimental characterization is infeasible. Therefore, a combination of numerical and experimental investigation is inevitable to get a deeper insight into the phenomenology of the fatigue behavior of concrete exposed to variable loading ranges. An enhanced $\mathrm{P}-\mathrm{M}$ rule based on a combined numericalexperimental investigation has been recently proposed by the authors [35].

The current paper presents a comprehensive experimental investigation of the load sequence effect on the fatigue behavior and establishes a basis for its general theoretical energetic explanation. In addition, it provides a qualitative validation using the extended $\mathrm{P}-\mathrm{M}$ rule, previously proposed in [35]. The paper starts with the description of the experimental program including the material properties of the tested concrete mixtures and of the six applied loading scenarios (Sect. 2). The experimental results of the concrete compressive behavior are presented in Sect. 3 including the analysis of primary dissipative mechanisms and evaluation of Wöhler curves, fatigue creep curves and of the sequence effect. In Sect. 4 the observed fatigue behavior is analyzed in terms of the dissipated energy, providing a basis for a general, theoretical explanation of the observed sequence effect. Finally, in Sect. 5 the existing assessment rules accounting for 
the sequence effect are briefly reviewed and validated using the presented experimental results.

\section{Experimental program}

\subsection{Material properties}

Three classes of concrete with different strength levels have been provided by an industry partner (MaxBögl). According to FIB Model Code 2010 [12] the concrete used in the study is classified into concrete strength classes C40/50, C80/90 and C120. For simplicity, the concrete classes are referred to as C40, C80 and C120 in the sequel. The properties of the three concrete classes are summarized in Table 2.

\subsection{Test program and data recording}

Compressive tests have been performed using cylinder test specimens with a diameter between $100-150 \mathrm{~mm}$ and a height of $300 \mathrm{~mm}$. The individual concrete grades were produced and tested within one batch to guarantee the consistency and comparability of the material properties, e.g. the maximum compressive strength and Young's modulus. The specimens remained in the formwork for 1 day before being immersed in water for 7 days. To ensure an adequate moisture content the specimens were sealed with a paraffin wax at the front surfaces. After these 7 days the cylinders were abraded and polished to achieve smooth and plane surfaces. After the treatment the specimens were stored in the lab. The tests were conducted 56 days after production, at the earliest.

The monotonic as well as the cyclic tests were carried out in a testing machine with a hydropuls actuator. Although the cylinders were polished, the load was introduced with the help of a flexible calotte. During the experiments the machine load and the strains of the concrete cylinders were measured continuously using linear variable differential transformers (LVDTs). Three LVDTs were placed between the steel support plates and distributed equally every $120^{\circ}$ (Fig. 1). Due to the explosive failure of the fatigue specimens, the LVDTs could not be attached to the specimen. Once the full stiffness of the specimen has been reached in the load displacement curves, the effect of machine deformation can be considered negligible, in particular during the fatigue loading. In

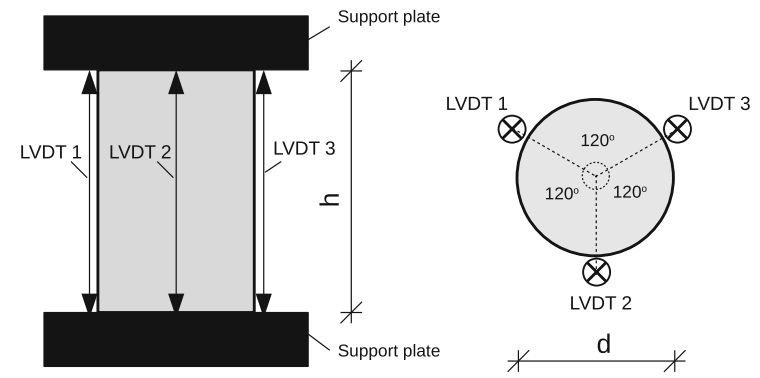

Fig. 1 Cylinder specimen geometry with 3 LVDTs positioned around the perimeter

this phase, we are primarily focusing on the strain trend evolution which delivers reproducible data at all studied levels. Therefore, we consider the applied procedure as a justified compromise. We would like to mention that the obtained results have been processed to subtract the initial deformation within the load introduction device.

\subsection{Loading scenarios}

To study the concrete fatigue behavior in a more comprehensible way and to extract rich amount of information on the concrete behavior under monotonic and cyclic compressive loading, a systematic set of loading scenarios has been introduced as summarized in Table 1. This set of loading scenarios introduces several independent observation perspectives to the material behavior. The purpose of such a test design is to provide a basis for a systematic calibration of simulation models and engineering design rules. Models can be calibrated using only a part of the observations, i.e. for monotonic and low-cycle loading scenarios. Subsequently, they can be validated using the other observations, represented e.g. by the test results obtained for high-cycle loading with varied amplitudes. The applied loading scenarios can be briefly characterized as follows:

LS1: The first loading scenario introduces a monotonically increasing control displacement/load with the rate of $1.0 \mathrm{~mm} / \mathrm{min}$ until failure. This test delivers the ultimate compression load $F_{\mathrm{u}}$.

LS2: The second loading scenario introduces a cyclic increasing control displacement for the upper and lower levels including four unloading cycles with the rate of $1.0 \mathrm{~mm} / \mathrm{min}$ until failure. This loading scenario provides detailed data on the loading and unloading behavior after the peak of the stress-strain 
Table 1 Description of the loading scenarios used in the experimental program

\begin{tabular}{|c|c|c|c|c|}
\hline $\begin{array}{l}\text { Loading } \\
\text { scenario }\end{array}$ & Description & Purpose & $\begin{array}{l}\text { Loading } \\
\text { rate/frequency }\end{array}$ & Figure \\
\hline LS1 & Monotonic loading & $\begin{array}{l}\text { Studying the monotonic behavior and } \\
\text { identifying the compressive strength }\end{array}$ & $1.0 \mathrm{~mm} / \mathrm{min}$ & $\mathrm{F}$, \\
\hline LS2 & Cyclic loading & $\begin{array}{l}\text { Providing detailed description of unloading } \\
\text { and reloading of the post-peak behavior }\end{array}$ & $1.0 \mathrm{~mm} / \mathrm{min}$ & \\
\hline LS3 & $\begin{array}{l}\text { Cyclic step-wise increased loading } \\
\text { with } 10 \text { cycles each level }\end{array}$ & $\begin{array}{l}\text { Providing detailed description of unloading } \\
\text { and reloading of the pre-peak behavior }\end{array}$ & $0.02 \mathrm{~Hz}$ & $S_{\max }$ \\
\hline LS4 & $\begin{array}{l}\text { Fatigue loading with step-wise } \\
\text { increasing levels }\end{array}$ & $\begin{array}{l}\text { Studying the fatigue behavior under increased } \\
\text { loading ranges }\end{array}$ & $5 \mathrm{~Hz}$ & $\mathrm{~S}_{\max }$ \\
\hline LS5 & $\begin{array}{l}\text { Fatigue loading with constant } \\
\text { amplitudes }\end{array}$ & $\begin{array}{l}\text { Characterizing the concrete fatigue under } \\
\text { constant amplitudes }\end{array}$ & $5 \mathrm{~Hz}$ & \\
\hline LS6 & $\begin{array}{l}\text { Fatigue loading with two loading } \\
\text { levels and different sequence }\end{array}$ & $\begin{array}{l}\text { Characterizing the sequence effect of the } \\
\text { fatigue loading }\end{array}$ & $5 \mathrm{~Hz}$ & \\
\hline
\end{tabular}

curve. This information is useful for the distinction of plasticity and damage mechanisms involved in the concrete compressive behavior. Moreover, the shape of the hysteretic loops of the stress-strain curve provides data on energy dissipation within the loading cycles.

LS3: The third scenario is a load-controlled cyclic loading with a moderate number of cycles i.e. 100 cycles. The load has been applied with a frequency of $0.02 \mathrm{~Hz}$. The upper load level started with $S^{\max }=0.5$ and increased step-wise by $\Delta S=0.05$ with 10 cycles performed at each load level. The lower load level was kept constant with $S^{\mathrm{min}}=0.1$ as shown in Table 1 . This loading scenario provides detailed data on the loading and unloading behavior, and delivers useful information on the rate of the damage accumulation at the subcritical load levels.

LS4: The fourth scenario is an accelerated loadcontrolled fatigue test with increasing loading range. The load has been applied with a frequency of $5 \mathrm{~Hz}$. This scenario is defined at three load levels starting at $S^{\text {max }}=0.6$ and $S^{\text {min }}=0.3$ and increasing incrementally by $\Delta S=0.1$ for both the upper and the lower load levels as shown in Table 1. Within the first and the second load levels, 350,000 cycles have been applied. The third load level was exposed to 35,000 loading cycles. If no fatigue failure occurred, the tests were loaded monotonically until failure. The purpose of this scenario is to study the concrete fatigue behavior under varying load ranges and to show the effect of the jump between the varying load levels. At the same time, the fatigue creep curves for an accelerated loading scenario with three load levels have been extracted.

LS5: The fifth scenario represents the standard fatigue loading with constant amplitudes. The load has been applied with a frequency of $5 \mathrm{~Hz}$. The upper load levels have been varied between $S^{\text {max }}=0.65$ to $S^{\text {max }}=0.85$, and lower load levels were set to $S^{\text {min }}=$ 0.05 and $S^{\mathrm{min}}=0.2$. The purpose of this scenario is to study the concrete fatigue behavior under constant amplitudes, and to extract the fatigue creep curves as well as the Wöhler curves.

LS6: The last scenario is a fatigue loading with two different levels applied in sequence i.e. high-low $(\mathrm{H}-$ L) and low-high (L-H). In these loading scenarios the 
first load level e.g. the high for $(\mathrm{H}-\mathrm{L})$ sequence is applied with a specific number of cycles, then the second load level is applied until fatigue failure. The load has been applied with a frequency of $5 \mathrm{~Hz}$. The upper load levels were similar to LS5. This loading scenario is the typical scenario to investigate the sequence effect on the fatigue life.

Loading frequency The loading scenarios (LS4, LS5, and LS6) have been run with the frequency of 5 $\mathrm{Hz}$. This frequency has been chosen with the goal to avoid heat generation in the specimen, which would develop at higher loading frequencies as shown e.g. in $[39,40]$. On the other hand, lower loading frequency would lead to a very long duration of the experiments. In the tests with cyclic step-wise loading scenario (LS3) a frequency of $0.02 \mathrm{~Hz}$ was used to allow a possibly perfect control of the upper and lower load limits by the testing machine, which would otherwise need a couple of cycles to stabilize the applied loading range.

Applied fatigue load levels The concrete fatigue behavior has been studied for high values of pre-peak load with the range of $60-85 \%$ of ultimate force. These values are considerably higher than the levels reached in large sections of concrete elements designed according to the current safety requirements on ultimate limit state, where the fatigue stresses are relatively small. In spite of this fact, we see an urgent need to provide a sound explanation of the concrete fatigue phenomenology for a broad range of applications. Since the reduction of the material consumption becomes an increasingly urgent issue, the range of stress-levels and the level of material utilization in future structural elements will significantly increase. An example of concrete material with a very utilization is provided by carbon textile reinforced concrete. Therefore, it is essential to study and understand the fatigue behavior within the full range of stress levels.

\subsection{Test program and observed phenomena}

The performed test campaign is summarized in Table 2 showing the correspondence between the concrete grades, the applied loading scenarios (LS1-LS6) and the performed replications of a particular test configuration.

The phenomenological aspects of the cyclic and fatigue behavior of concrete that are going to be included in the evaluation and interpretation of the experimental results are displayed in Fig. 2. They can be briefly characterized as follows:

- Dissipative mechanisms: defining the inelastic processes occur within the material structures which are responsible for the energy dissipation during the loading history such as the stiffness degradation and the development of irreversible strains.

- Hysteretic loops: representing the history dependence of the stress-strain relationship upon loading and reloading [41-45] and the relation to energy dissipation owing to the internal friction [46, 47].

- Fatigue creep curves: showing the nonlinear strain evolution during fatigue life with rapid strain growth in the first and the last stages and moderate, nearly linear strain growth in the middle stage [48-52].

- Wöhler curves: defining the fatigue life under constant cyclic loading range i.e describing the relation between cyclic stress amplitude and the number of cycles to failure [53-58].

- Loading sequence effect: representing the dependency of the concrete fatigue behavior on the loading sequence which has been observed experimentally by many authors $[6,18,19,24,35,36]$. This complex fatigue phenomenon can be used to critically evaluate the model ability to reflect the loading sequence effect under variable loading ranges.

\section{Experimental results and discussion}

The test results obtained for the monotonic loading (LS1) are summarized in Table 3 followed by the results for cyclic and fatigue loading scenarios (LS3LS5) in Table 4. The experimental results of the fatigue tests especially the high-cycle fatigue tests have been extracted using a software tool with multiple filtering features and a graphical user interface named High-Cycle Fatigue Tool (HCFT) provided in [59].

\subsection{Monotonic loading (LS1)}

Compressive strength and concrete grades The average characteristic values of concrete compressive behavior of the three tested concrete mixtures are 
Table 2 Properties of the tested concrete mixtures and test matrix

\begin{tabular}{|c|c|c|c|c|c|c|c|c|c|c|c|}
\hline \multirow{2}{*}{$\begin{array}{l}\text { Concrete } \\
\text { grade }\end{array}$} & \multirow[t]{2}{*}{ Cement } & \multirow{2}{*}{$\begin{array}{l}\mathrm{W} / \\
\mathrm{C}\end{array}$} & \multirow[t]{2}{*}{ Aggregate type } & \multirow{2}{*}{$\begin{array}{l}\text { Maximum } \\
\text { grain size }\end{array}$} & \multirow{2}{*}{$\begin{array}{l}\text { Cylinder } \\
\text { dimensions } \\
\mathrm{d} \times \mathrm{h}(\mathrm{mm})\end{array}$} & \multicolumn{6}{|c|}{ Loading scenario } \\
\hline & & & & & & LS1 & LS2 & LS3 & LS4 & LS5 & LS6 \\
\hline $\mathrm{C} 40$ & $\begin{array}{l}\text { CEM II } \\
42,5 \mathrm{~N}\end{array}$ & 0.50 & $\begin{array}{l}62 \% \text { limestone, } 38 \% \\
\text { quartz }\end{array}$ & $8 \mathrm{~mm}$ & $150 \times 300$ & 9 & 3 & 2 & 1 & 24 & 24 \\
\hline $\mathrm{C} 80$ & $\begin{array}{l}\text { CEM I 52,5 } \\
\text { R }\end{array}$ & 0.47 & $\begin{array}{l}50 \% \text { limestone, } 50 \% \\
\text { quartz }\end{array}$ & $16 \mathrm{~mm}$ & $100 \times 300$ & 10 & - & 3 & 1 & 25 & 12 \\
\hline $\mathrm{C} 120$ & $\begin{array}{l}\text { CEM I 52,5 } \\
\text { R }\end{array}$ & 0.35 & $100 \%$ quartz & $16 \mathrm{~mm}$ & $100 \times 300$ & 6 & - & 3 & 3 & 9 & - \\
\hline
\end{tabular}
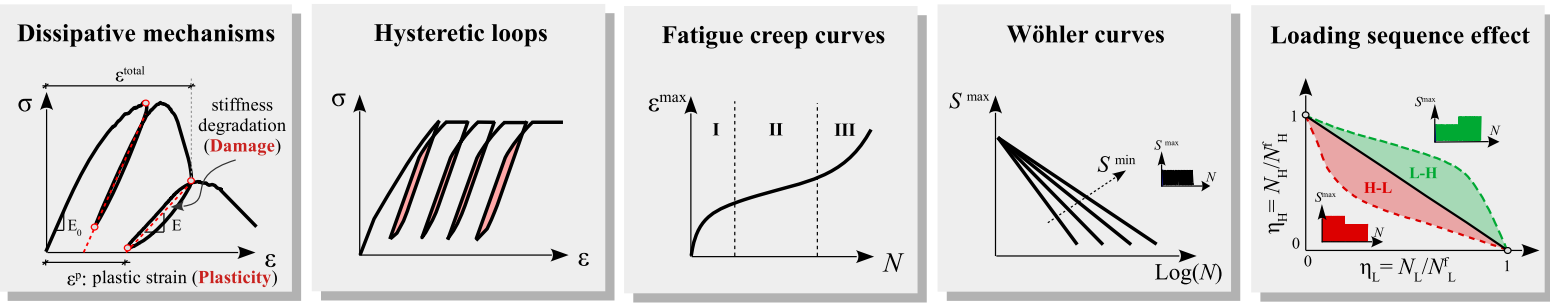

Fig. 2 The main phenomenological aspects of cyclic and fatigue behavior of concrete

Table 3 Summary of the monotonic tests with statistical evaluation of results

\begin{tabular}{|c|c|c|c|c|c|c|c|c|c|}
\hline Tests & Concrete & $\begin{array}{l}\text { Loading } \\
\text { scenario }\end{array}$ & No. of tests & $\boldsymbol{F}_{\mathrm{u}}(\mathrm{kN})$ & $\begin{array}{l}f_{\mathrm{c}} \\
(\mathrm{MPa})\end{array}$ & $\begin{array}{l}\text { SD } \\
(\mathrm{MPa})\end{array}$ & $\begin{array}{l}\mathrm{CoV} \\
(\%)\end{array}$ & $\varepsilon_{\mathrm{c}}(-)$ & $\begin{array}{l}\boldsymbol{E} \\
(\mathrm{MPa})\end{array}$ \\
\hline T-C40[01-09] & $\mathrm{C} 40$ & LS1 & 9 & 1087.60 & 61.55 & 2.33 & 3.79 & 0.0033 & 31900 \\
\hline T-C80[01-10] & $\mathrm{C} 80$ & LS1 & 10 & 796.24 & 101.38 & 7.61 & 7.51 & 0.0035 & 34500 \\
\hline T-C120[01-06] & $\mathrm{C} 120$ & LS1 & 6 & 964.34 & 122.78 & 1.67 & 1.36 & 0.0031 & 42500 \\
\hline
\end{tabular}

summarized in Table 3. These values are the compressive strength $f_{\mathrm{c}}$, the compressive strain at the maximum force $\varepsilon_{\mathrm{c}}$, and the elastic compressive stiffness $E$. The stress-strain curves obtained for the three used concrete grades are depicted in Fig. 3a-c. Only for the concrete $\mathrm{C} 40$ the post-peak response has been measured, as in this test displacement control was used, see Fig. 3a. For the concrete grades C80 and C120, load control was used up to the peak as plotted in Fig. 3b, c.

Scatter of the compressive strength The scatter of the compressive strength is provided in Table 3. The high strength concrete $\mathrm{C} 120$ shows lower scatter with coefficient of variation $(\mathrm{CoV})$ of $1.67 \%$. The specimens of the concrete grade C80 reveal a larger scatter with coefficient of variation $(\mathrm{CoV})$ of $7.51 \%$. This level of scatter is high and makes a reproducible investigation of the fatigue behavior nearly impossible [60-64]. Therefore, to reduce the scatter of the test results for the subsequently tested concrete grade C40, two changes of the test setup have been adapted. The specimen diameter has been increased to $150 \mathrm{~mm}$ instead of $100 \mathrm{~mm}$ as specified in Table 2, and a smaller maximum grain size of $8 \mathrm{~mm}$ was used in the concrete mixture instead of $16 \mathrm{~mm}$ used for the concrete grades C80 and C120. These modification indeed lead to a significant reduction of the scatter with the coefficient of variation $(\mathrm{CoV})$ of $3.79 \%$. As 
Table 4 Summary of the cyclic and fatigue tests (LS3, LS4, LS5)

\begin{tabular}{|c|c|c|c|c|c|c|c|c|}
\hline Test & Concrete & $\begin{array}{l}\text { Loading } \\
\text { scenario }\end{array}$ & $\begin{array}{l}\text { No. of } \\
\text { tests }\end{array}$ & $S^{\max }$ & $S^{\min }$ & $\begin{array}{l}\text { Average no. of } \\
\text { cycles }\end{array}$ & $\begin{array}{l}\text { Max no. of } \\
\text { cycles }\end{array}$ & $\begin{array}{l}\text { Min no. of } \\
\text { cycles }\end{array}$ \\
\hline T-C40[13,14] & $\mathrm{C} 40$ & LS3 & 2 & $(0.5-0.95)$ & 0.1 & 100 & 100 & 100 \\
\hline T-C40[15] & $\mathrm{C} 40$ & LS4 & 1 & $(0.6 / 0.7 / 0.8)$ & $(0.3 / 0.4 / 0.5)$ & 735000 & - & - \\
\hline T-C40[16-28] & $\mathrm{C} 40$ & LS5 & 13 & 0.65 & 0.05 & 1244440 & 4867922 & 18043 \\
\hline T-C40[29-39] & $\mathrm{C} 40$ & LS5 & 11 & 0.75 & 0.05 & 31400 & 64158 & 6094 \\
\hline T-C80[11-13] & $\mathrm{C} 80$ & LS3 & 3 & $(0.5-0.95)$ & 0.1 & 88 & 91 & 86 \\
\hline T-C80[14] & $\mathrm{C} 80$ & LS4 & 1 & $(0.6 / 0.7 / 0.8)$ & $(0.3 / 0.4 / 0.5)$ & 469110 & - & - \\
\hline T-C80[15-17] & $\mathrm{C} 80$ & LS5 & 3 & 0.65 & 0.2 & 2433088 & 3074229 & 2065037 \\
\hline T-C80[18-27] & $\mathrm{C} 80$ & LS5 & 10 & 0.75 & 0.2 & 395250 & 2012546 & 74190 \\
\hline $\mathrm{T}-\mathrm{C} 80[28-31]$ & $\mathrm{C} 80$ & LS5 & 4 & 0.80 & 0.2 & 17319 & 32173 & 7835 \\
\hline T-C80[32-39] & $\mathrm{C} 80$ & LS5 & 8 & 0.85 & 0.2 & 4868 & 13713 & 647 \\
\hline T-C120[07-09] & $\mathrm{C} 120$ & LS3 & 3 & $(0.5-0.95)$ & 0.1 & 100 & 100 & 100 \\
\hline $\mathrm{T}-\mathrm{C} 120[10-12]$ & $\mathrm{C} 120$ & LS4 & 3 & $(0.6 / 0.7 / 0.8)$ & $(0.3 / 0.4 / 0.5)$ & 735000 & 735000 & 735000 \\
\hline T-C120[13-16] & $\mathrm{C} 120$ & LS5 & 4 & 0.75 & 0.2 & 1942093 & 5626000 & 6750 \\
\hline $\mathrm{T}-\mathrm{C} 120[17-21]$ & $\mathrm{C} 120$ & LS5 & 5 & 0.85 & 0.2 & 14880 & 24881 & 5755 \\
\hline
\end{tabular}

we show later on, the scatter reduction helped to make the trends in the experimental study of the loading sequence effect clearer.

\subsection{Cyclic loading (LS2)}

Stress-strain curve and hysteretic loops To trigger a possibly broad range of dissipative mechanisms within the material structure, the concrete specimens were exposed to several displacement controlled loading cycles covering also the post-peak regime. This loading scenario (LS2) has been applied to concrete grade $\mathrm{C} 40$. Particular focus of the test evaluation was on the changing shape of the hysteretic loops as shown in Fig. 3d. The area of a hysteretic loop provides a measure of energy dissipation within individual loading cycles [65].

Evaluation of the dissipative mechanisms Testing the concrete compressive behavior under cyclic loading (LS2) is essential for the macroscopic distinction of the dissipative mechanisms leading to the degradation of the concrete strength in the post-peak regime of a displacement controlled, monotonic test. The primary dissipative mechanisms are the plastic strain evolution and the degradation of the unloading stiffness which defines the value of damage [66-68].

The plastic strain $\varepsilon^{\mathrm{P}}$ can be obtained for each point of the stress-strain $(\sigma-\varepsilon)$ curve as follow [69]
${ }_{\varepsilon}^{\mathrm{P}}=\varepsilon-\frac{\sigma}{E}$,

where $E$ is the corresponding unloading stiffness at each point of the stress-strain curve.

The damage parameter which is representing the fraction of the material that has been damaged can be obtained as

$\omega=1-\frac{E}{E_{0}}$,

where $E_{0}$ is the initial elastic stiffness.

The plastic strain and damage parameter is depicted in Fig. 3e, f for C40 tests, respectively. It is apparent from Fig. $3 \mathrm{e}$ that the onset of the plastic strain is in the pre-peak range. Up to the peak, plastic strain increases rapidly, accompanied by a moderate growth of damage. In the post-peak regime, the damage evolution becomes more significant and governs the softening behavior. Similar observations have been reported in the literature by many authors e.g. [69, 70]. Another phenomenological correspondence might be established between the uniformly distributed dissipation within the volume of the specimen in the pre-peak regime and primarily plastic energy dissipation. On the other hand, in the post-peak regime with crack localization leading to a cone shaped failure mode, the energy dissipation can be primarily ascribed to damage mechanisms. These observations 

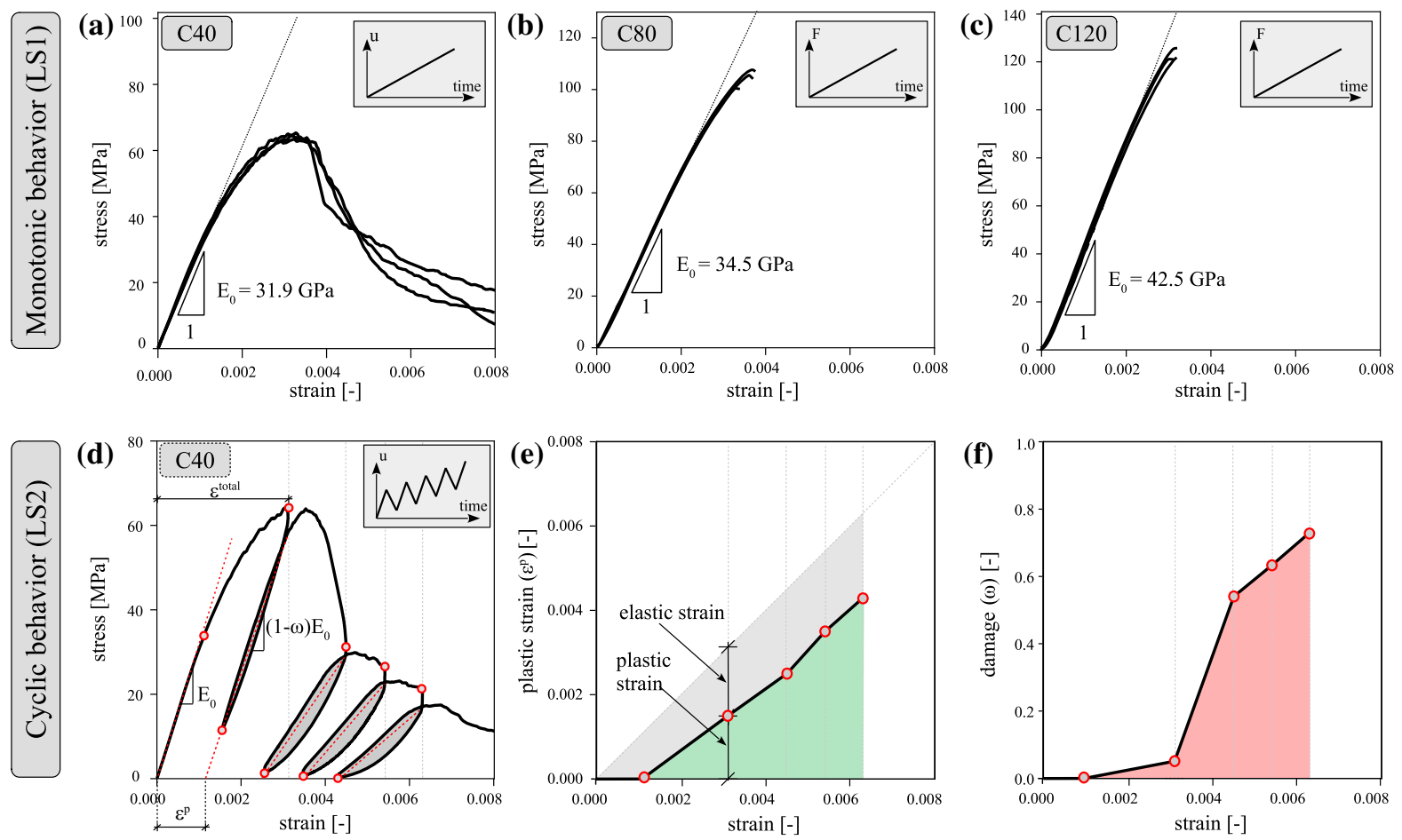

Fig. 3 Monotonic and cyclic behavior of the tested concrete: a-c stress-strain response under monotonic loading (LS1) for concrete grades C40, C80, and C120, respectively; d cyclic stress-strain response of concrete C40 under the loading scenario (LS2) e corresponding plastic strain evolution; f corresponding damage evolution

can be regarded as a primary input for assessing and developing of advanced numerical models based on the damage and plasticity theory to capture the cyclic behavior of concrete.

\subsection{Step-wise cyclic loading (LS3)}

Stress-strain response The load-displacement curves of one selected test from each series with concrete mixtures C40, C80 and C120 loaded with step-wise increasing cyclic scenario (LS3) are depicted in Fig. 4a-c. As discussed in the context of LS2, during a pre-peak cyclic loading, the major mechanism of inelastic dissipation is the plastic strain development. This can be recognized from the unloading stiffness of individual cycles exhibiting large irreversible strain. Even though the unloading level was set only to $S^{\text {min }}=10 \%$, the recorded values of strain at the upper and the lower load levels can be used to evaluate the fractions of reversible and irreversible strains. The behavior also shows a small reduction of the unloading stiffness that can be quantified by comparing the unloading stiffness in the last and first loading cycle.

Fatigue creep curves The growth of the strain i.e. the fatigue creep curve at the upper and lower levels of loading for the three concrete types is plotted in Fig. $4 d-f$. These fatigue creep curves show an increase of the strain rate with the increase of the subcritical load level. Qualitatively similar response is observed for all three types of concrete mixture. The average number of cycles up to the failure and the corresponding minimum and maximum values are summarized in Table 4.

\subsection{Step-wise increasing fatigue loading levels (LS4)}

Fatigue creep curves The results obtained for scenario LS4 are plotted in terms of fatigue creep curves in Fig. 5 for the three tested concrete types. The test with concrete C80 showed a fatigue failure at the second load level after 469,110 cycles. The tests with concrete grades C40 and C120 survived the total of 735,000 

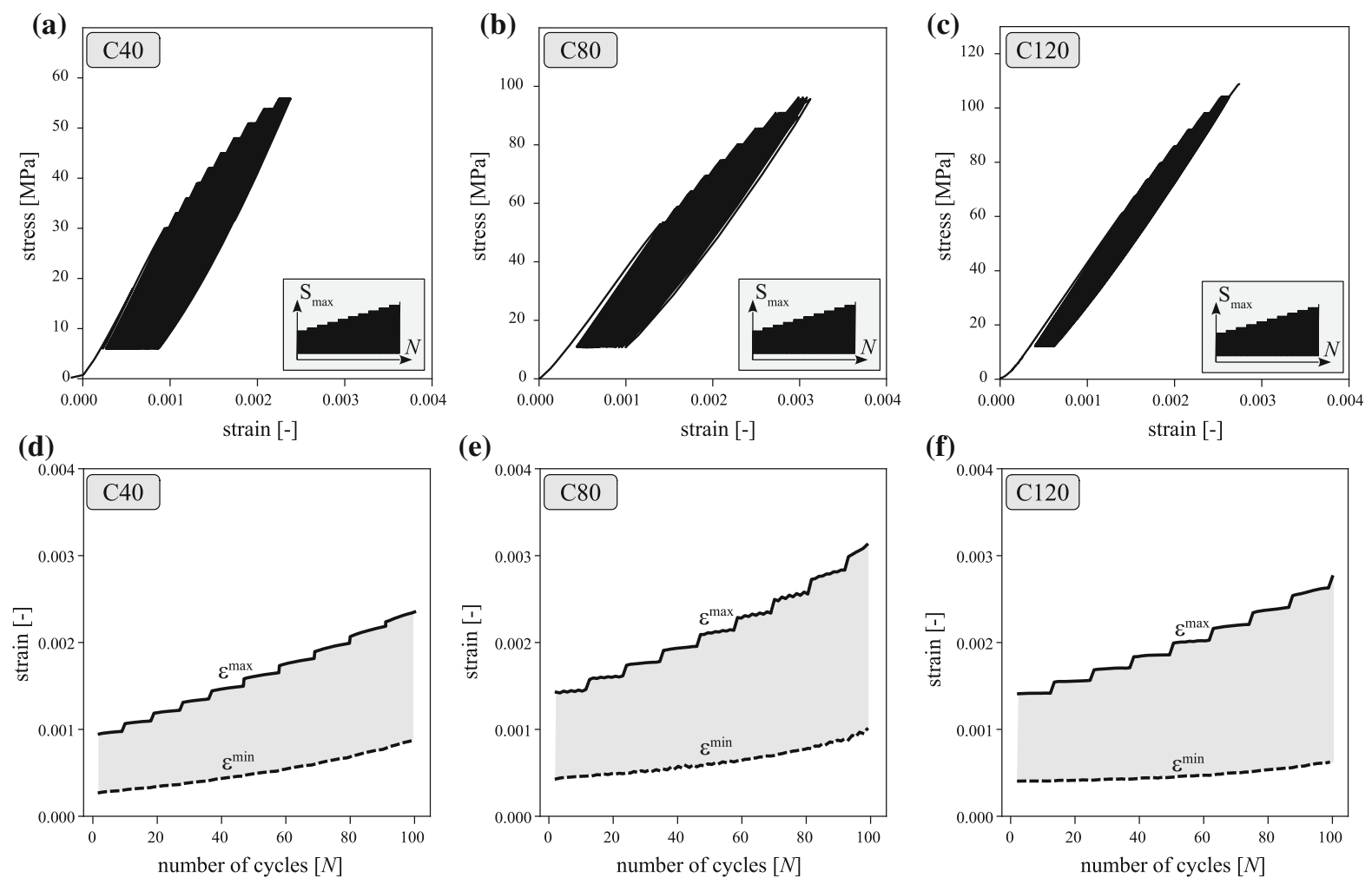

Fig. 4 Cyclic behavior of three concrete grades under the loading scenario (LS3): $\mathbf{a}-\mathbf{c}$ stress-strain response; $\mathbf{d}-\mathbf{g}$ fatigue creep curves i.e. strain development at the upper load level during cyclic loading

cycles given by the scenario and were subsequently loaded monotonically until failure. For these two tests, no reduction of the residual compressive strength was observed for the applied fatigue loading. This is probably due to the small amplitude within the stepwise increasing load ranges of $30 \%$ which is not large enough to accumulate a sufficient amount of fatigue damage that would lead to an ultimate failure. Let us remark that the test depicted in Fig. 5 reveals problems with the machine load control that occurred during the second phase of loading. Still, as the original trend could be recovered after fixing this problem, we consider the result of this test relevant for the performed comparison.

The number of cycles within each load step was set a-priori. The primary purpose of the scenario LS4 was to rapidly obtain a shape of the segments of fatigue creep curve at several load levels using a single test. This perspective on the changes in the material behavior during the cyclic loading can serve for a model validation on a wide range of cycling load levels. As expected, a rapid growth of the strain at the third load range was observed as shown in Fig. 5c.

\subsection{Uniform fatigue loading (LS5)}

Fatigue creep curves The fatigue creep curves under constant amplitudes for representative tests of each concrete grade are plotted in Fig. 6a, b, d, e, g, h. The typical shape of fatigue creep curves the rapid increase of the strain in the first and last stages and nearly linear growth in the middle stage is reproduced in all tests. It can be observed that the range of strain growth between the first and last cycle is inversely proportional to the compressive strength, i.e. larger strength leads to smaller strain difference. Two different upper load levels $\mathrm{L}$ and $\mathrm{H}$ have been used for each concrete grade shown in the first and second columns of Fig. 6, respectively. By comparing the two columns, we can also conclude that the range of strain decreases with an increasing the load level.

Wöhler curves The number of cycles to fatigue failure for varied upper load levels $S^{\text {max }}$ measured in 

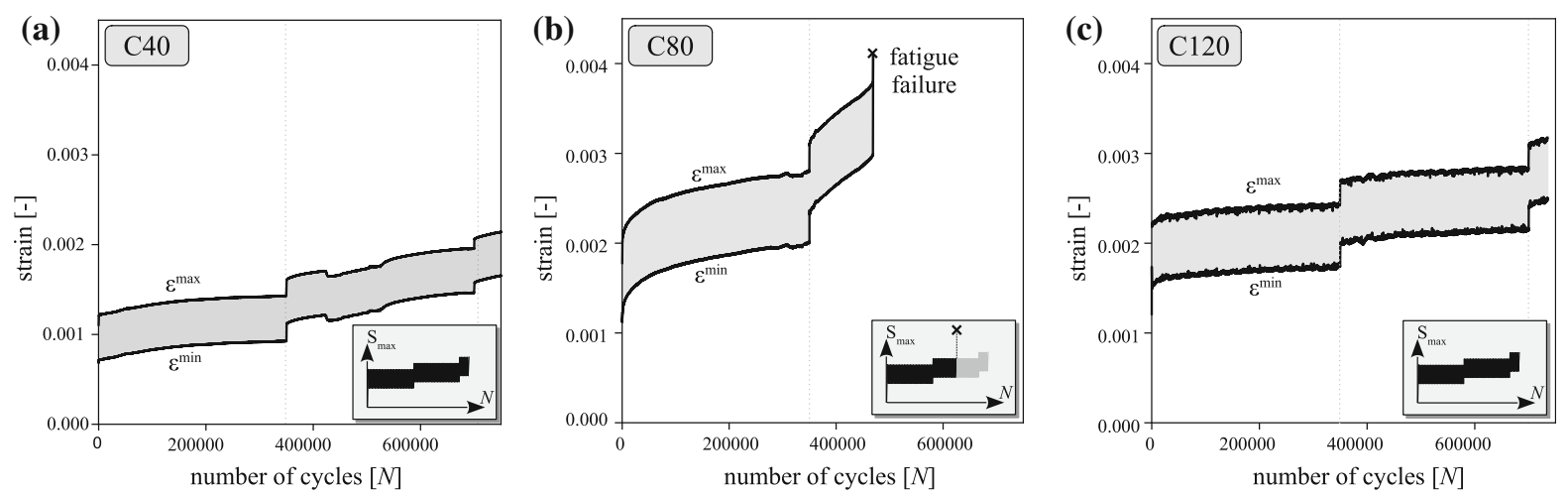

Fig. 5 Fatigue response of three concrete grades to the varying loading scenario (LS4): a concrete grade C40; b concrete grade C80; c concrete grade $\mathrm{C} 120$

the performed tests of the concrete $\mathrm{C} 40, \mathrm{C} 80$ and $\mathrm{C} 120$ is summarized in Fig. 6c, f, i, respectively. The numerical values for the investigated load levels including the average, minimum and maximum values of the number of cycles to fatigue failure are included in Table 4.

The fib Model Code 2010 [12] proposes an empirical approximation of Wöhler curves for the normal- and high-strength concrete by defining the number of cycles to failure in the range $\log (N) \leq 8$ as

$\log N_{\mathrm{f}}=\frac{8}{Y-1}\left(S^{\max }-1\right)$,

where

$$
Y=\frac{0.45+1.8 S^{\min }}{1+1.8 S^{\min }-0.3\left(S^{\min }\right)^{2}} .
$$

The regression line for the obtained test results of concrete C80 matches well with the Wöhler curve evaluated using the approximation Eq. (4). For concrete grades $\mathrm{C} 40$ and $\mathrm{C} 120$, the obtained results show longer fatigue life than predicted by the fib Model Code 2010. However, for a relevant comparison more tests would be necessary. Still, for the investigation of the loading sequence effect such number of specimens are reasonable to determine the fatigue life of the individual loading ranges.

It is worth to mention that while several values of the upper load levels are required to obtain Wöhler curves, two load levels are sufficient for the study of the sequence effect as presented for C40. In case of $\mathrm{C} 80$ an additional load level has been included in order to tune the test parameters for the investigation of the sequence effect. For $\mathrm{C} 120$ the limited number of the specimens did not allow to test more loading levels.

\subsection{Sequence of two loading ranges (LS6)}

The effect of loading sequence is investigated using a loading scenario consisting of two loading ranges with the upper load levels $(\mathrm{H})$ and $(\mathrm{L})$. Each loading range applied separately would lead to failure after $N_{\mathrm{H}}^{\mathrm{f}}$ and $N_{\mathrm{L}}^{\mathrm{f}}$ loading cycles. The question is what number of loading cycles leads to fatigue failure when the two loading ranges are combined in a sequence, either (HL) or $(\mathrm{L}-\mathrm{H})$. The obtained experimental results of concrete $\mathrm{C} 40$ and $\mathrm{C} 80$ are summarized in Table 5 and plotted in Fig. 7. The test results are visualized in relation to the Palmgren-Miner $\mathrm{P}-\mathrm{M}$ rule providing a baseline for the evaluation of the sequence effect. Assuming that the first loading range consumed 20\% of its fatigue life, i.e. $0.2 N_{\mathrm{H}}^{\mathrm{f}}$, the $\mathrm{P}-\mathrm{M}$ rule suggests that the second loading range would consume the respective $80 \%, 0.8 N_{\mathrm{L}}^{\mathrm{f}}$ of its fatigue life, immaterial of the order of loading range application. The diagrams in Fig. 7 show to what extent do the obtained results agree with this assumption.

Fatigue creep curves The fatigue creep curves obtained for the (H-L) and $(\mathrm{L}-\mathrm{H})$ loading scenarios are depicted in Fig. 7a, b for concrete C40, and in Fig. $7 d$, e for concrete C80. For comparison, the experimental results presented by [18] are included in Fig. $7 \mathrm{~g}$, h. The lifetime on the horizontal axis is normalized with respect to the lifetime prediction by the $\mathrm{P}-\mathrm{M}$ rule assuming the fatigue failure once the sum of the consumed fatigue life $\sum \eta$ of both $(\mathrm{H})$ and $(\mathrm{L})$ is 

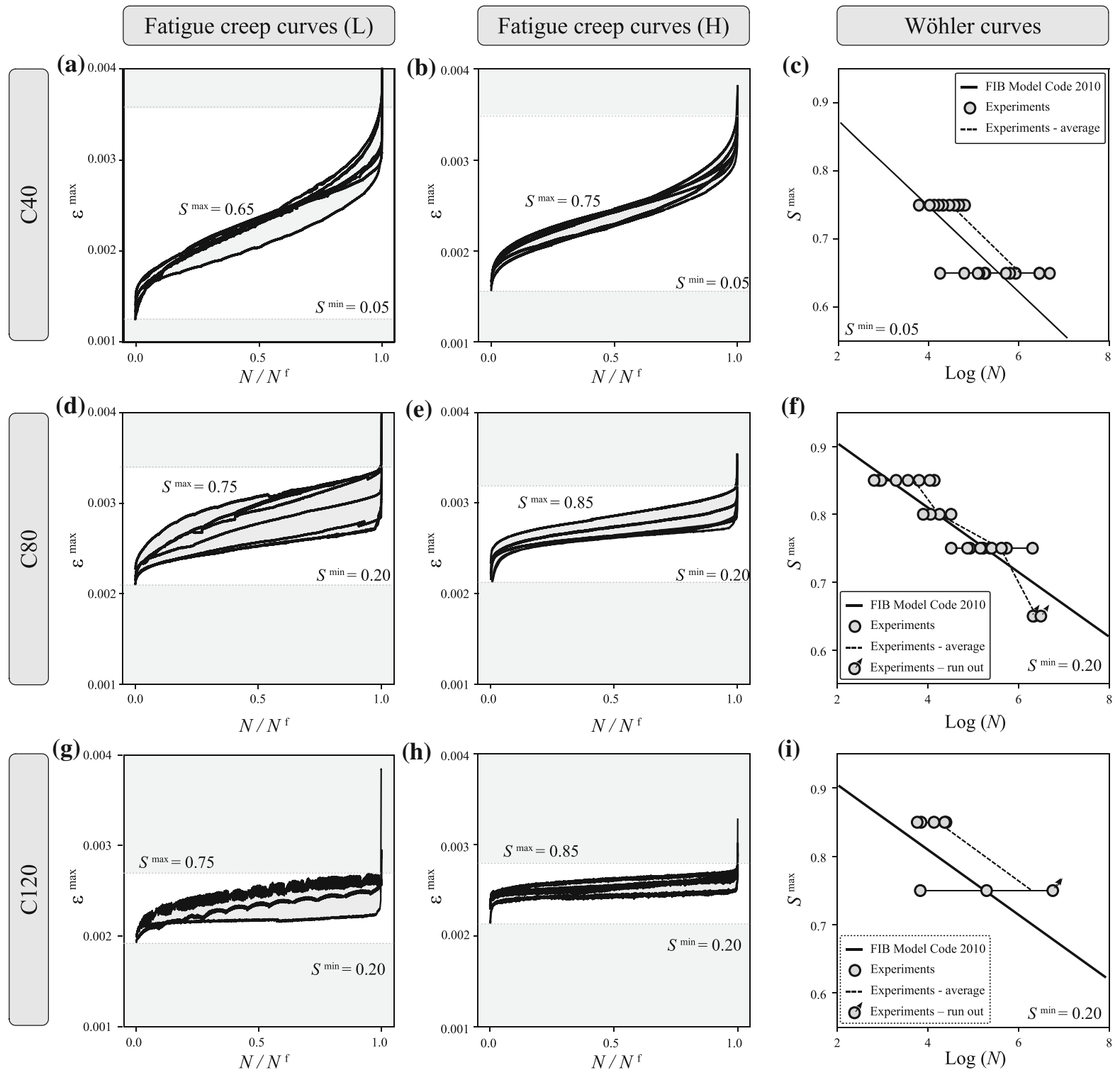

Fig. 6 Fatigue response of three concrete grades under constant amplitudes loading scenario (LS5): a, b fatigue creep curves for concrete $\mathrm{C} 40$; $\mathbf{c}$ Wöhler curve for concrete $\mathrm{C} 40 ; \mathbf{d}$, e fatigue creep curves for concrete $\mathrm{C} 80 ; \mathbf{f}$ Wöhler curve for concrete C80; $\mathbf{g}$, h fatigue creep curves for concrete $\mathrm{C} 120$; i Wöhler curve for concrete $\mathrm{C} 120$

equal to 1 . The average values of the consumed fatigue life of the first and second loading ranges are summarized in Table 5. Even though the results show a considerable scatter, an obvious trend can be observed. For concrete C40 the average of the consumed fatigue life sum $\sum \eta$ is less than 1.0 for the $(\mathrm{H}-\mathrm{L})$ sequence depicted in Fig. 7a, and larger than 1.0 for the $(\mathrm{L}-\mathrm{H})$ sequence depicted in Fig. $7 \mathrm{~b}$. This indicates an unsafe prediction of the $\mathrm{P}-\mathrm{M}$ rule for
(H-L) scenario and conservative prediction of $(\mathrm{L}-\mathrm{H})$ scenario. These results confirm the observation presented by [18] shown in Fig. 7g, h. For concrete C80, the results show a considerably larger scatter and the obtained average values of the consumed fatigue life sum $\sum \eta$ are larger than 1.0 both for $(\mathrm{H}-\mathrm{L})$ and for $(\mathrm{L}-$ $\mathrm{H})$ sequences. Still, the fatigue life sum is significantly smaller for $(\mathrm{H}-\mathrm{L})$ compared to $(\mathrm{L}-\mathrm{H})$. 
Table 5 Summary of the cyclic and fatigue tests (LS6)

\begin{tabular}{llllllllllllll}
\hline Test & Concrete & $\begin{array}{l}\text { Loading } \\
\text { scenario }\end{array}$ & $\begin{array}{l}\text { Loading } \\
\text { sequence }\end{array}$ & $\begin{array}{l}\text { No. of } \\
\text { tests }\end{array}$ & $S_{\mathrm{H}}^{\max }$ & $S_{\mathrm{L}}^{\max }$ & $\boldsymbol{S}^{\min }$ & $\eta_{\mathrm{H}}$ & $\eta_{\mathrm{L}}$ & $\begin{array}{l}\sum \eta \\
\begin{array}{l}\text { Average } \\
\left(\sum \eta\right)\end{array}\end{array}$ & $\begin{array}{l}\text { Max } \\
\left(\sum \eta\right)\end{array}$ & $\begin{array}{l}\text { Min } \\
\left(\sum \eta\right)\end{array}$ \\
\hline T-C40[40-45] & C40 & LS6 & H-L & 6 & 0.75 & 0.65 & 0.05 & 0.15 & 0.41 & 0.56 & 0.75 & 1.4 & 0.3 \\
T-C40[46,47] & C40 & LS6 & H-L & 2 & 0.75 & 0.65 & 0.05 & 0.16 & 0.40 & 0.56 & \\
T-C40[48-50] & C40 & LS6 & H-L & 3 & 0.75 & 0.65 & 0.05 & 0.47 & 0.77 & 1.24 & \\
T-C40[51-56] & C40 & LS6 & L-H & 6 & 0.75 & 0.65 & 0.05 & 1.24 & 0.05 & 1.29 & 1.33 & 2.44 & 0.54 \\
T-C40[57,58] & C40 & LS6 & L-H & 2 & 0.75 & 0.65 & 0.05 & 1.45 & 0.13 & 1.57 & & \\
T-C40[59-61] & C40 & LS6 & L-H & 3 & 0.75 & 0.65 & 0.05 & 0.67 & 0.18 & 0.85 & & \\
T-C40[62,63] & C40 & LS6 & L-H & 2 & 0.75 & 0.65 & 0.05 & 1.52 & 0.36 & 0.85 & & \\
T-C80[40-43] & C80 & LS6 & H-L & 4 & 0.85 & 0.75 & 0.20 & 0.24 & 1.08 & 1.32 & 1.27 & 2.34 & 0.54 \\
T-C80[44-46] & C80 & LS6 & H-L & 3 & 0.85 & 0.75 & 0.20 & 0.47 & 0.73 & 1.20 & \\
T-C80[47-49] & C80 & LS6 & L-H & 3 & 0.85 & 0.75 & 0.20 & 2.33 & 0.09 & 2.42 & 2.24 & 3.6 & 1.37 \\
T-C80[50,51] & C80 & LS6 & L-H & 2 & 0.85 & 0.75 & 0.20 & 1.72 & 0.26 & 1.98 & \\
\hline
\end{tabular}

Scale of material heterogeneity and scatter of test results As discussed earlier in Sec. 3.1, the scatter of results obtained for $\mathrm{C} 80$ was almost twice as large as for $\mathrm{C} 40$ in the monotonic test. It is well known that the scatter observed in the monotonic test gets amplified in fatigue tests. This fact makes a reproducible observation of trends in response extremely difficult. In the case of C80 specimens which were agreed upon and shared across several test campaigns conducted within a collaborative research program WinConFat including seven German universities, the ratio of the maximum aggregate size and of the specimen dimensions was $16 / 100$. This large ratio can result in very different spatial aggregate distribution within the specimen volume leading to different evolution of failure modes and, thus, to a large scatter. To reduce the scatter, the authors modified the test specimens for C80 by using an $8 \mathrm{~mm}$ maximum aggregate size and the cylinder diameter of $150 \mathrm{~mm}$ to obtain the ratio 8/150. The desired reduction of the scatter could then indeed be reproduced in the test results, providing a better chance to reproduce the sequence effect in to the two-range loading scenario LS6.

Comparison with $\mathrm{P}-\mathrm{M}$ rule The results of all tests with $(\mathrm{H}-\mathrm{L})$ and $(\mathrm{L}-\mathrm{H})$ loading scenarios are compared with the $\mathrm{P}-\mathrm{M}$ rule and plotted in terms of consumed fatigue life diagrams in Fig. 7c, f, i. The horizontal and vertical axes in these graphs $\eta_{\mathrm{L}}, \eta_{\mathrm{H}}$ represent the consumed fatigue life obtained with the lower (L) and higher $(\mathrm{H})$ load ranges, respectively. The value of $S^{\text {min }}$ has been set constant for both lading ranges. A combined loading scenario consisting of two load levels e.g. (H-L) is visualized by connected vertical and horizontal arrows. The vertical arrow represents a cycling with a higher value of $S^{\max }(\mathrm{H})$, whereas the horizontal one corresponds to a lower value (L). This means that the $(\mathrm{H}-\mathrm{L})$ scenario depicted with the red arrows in Fig. 7c first started with the higher load range $(\mathrm{H})$ and consumed $15 \%$ of the lifetime, as shown by the vertical arrow starting from zero. In the second stage, cycles with the lower load range (L) were applied until fatigue failure occurred, as indicated by the red horizontal arrow.

For concrete $\mathrm{C} 40$, it can be observed that the majority of the (H-L) tests fail earlier than predicted by the $\mathrm{P}-\mathrm{M}$ rule, while most of the $(\mathrm{L}-\mathrm{H})$ tests show longer fatigue life than the $\mathrm{P}-\mathrm{M}$ rule prediction as shown in Fig. 7c. This is consistent with the observation presented by Holmen [18] plotted in Fig. 7i. In case of the C80 concrete depicted in Fig. $7 \mathrm{f}$ all tests exhibit a longer fatigue life than the $\mathrm{P}-\mathrm{M}$ rule prediction. Still, in view of the $\mathrm{P}-\mathrm{M}$ linear scaling, the $(\mathrm{L}-\mathrm{H})$ scenario results in a longer lifetime than the $(\mathrm{H}-\mathrm{L})$ scenario, which is in agreement with the trend observed in the other test series.

Time-dependent concrete strength Any test program that focuses on fatigue must address the issue of time-dependent concrete strength. Due to the long duration of the tests and the usually limited capacity of the test facilities, it is not possible to perform all tests within a short time window to ensure that all test specimens are of comparable age. In the present study all test specimens were produced simultaneously in 


\section{Fatigue creep curves (H-L)}
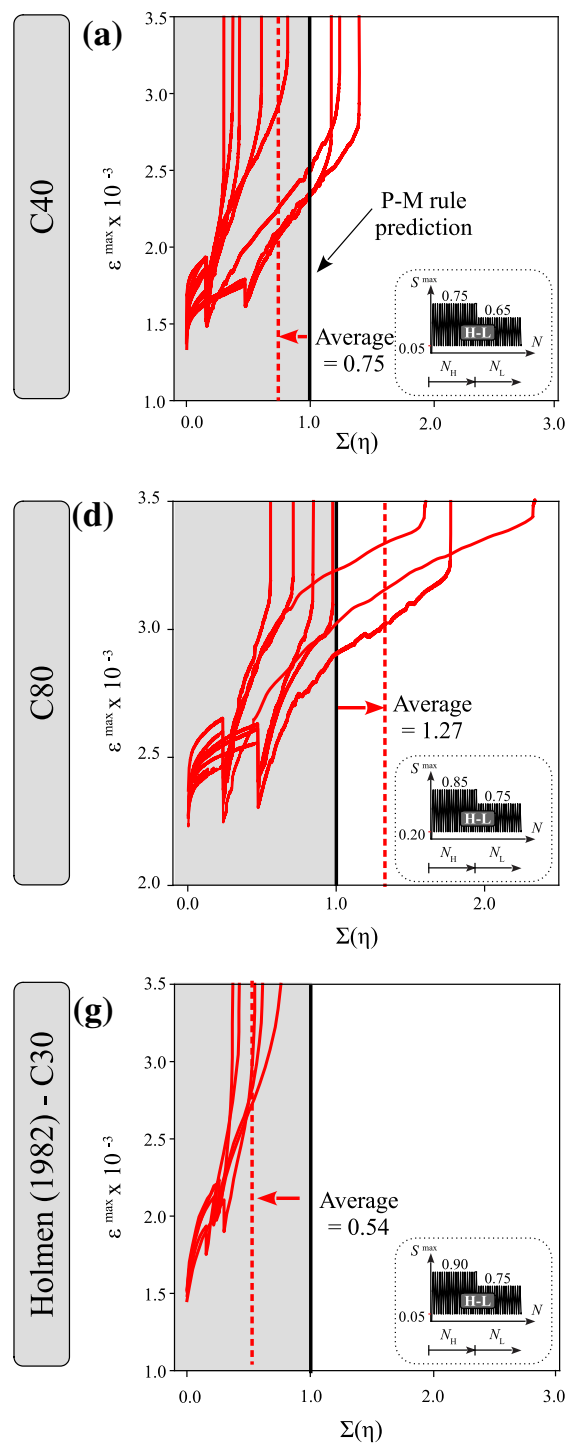

Fatigue creep curves (L-H)
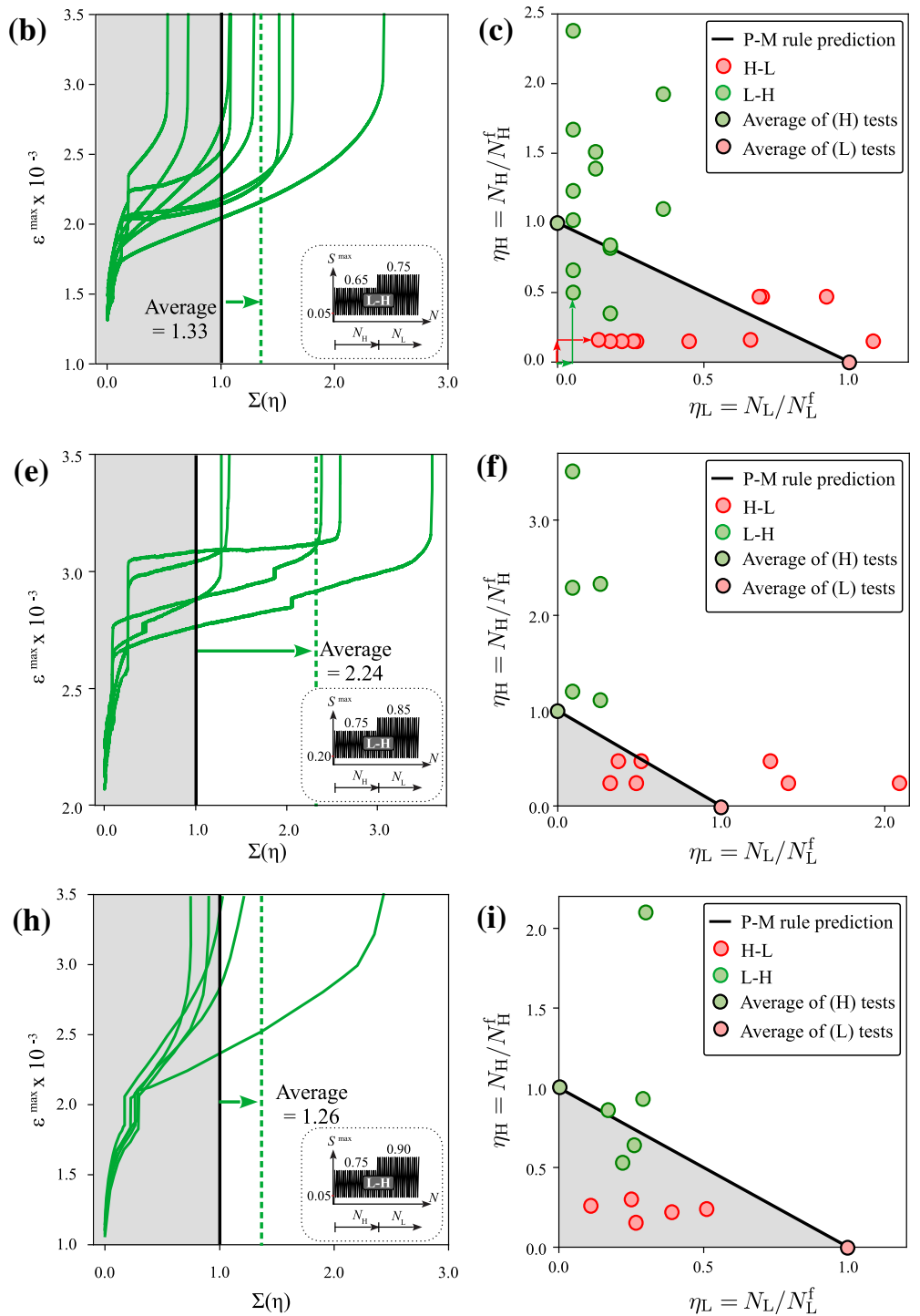
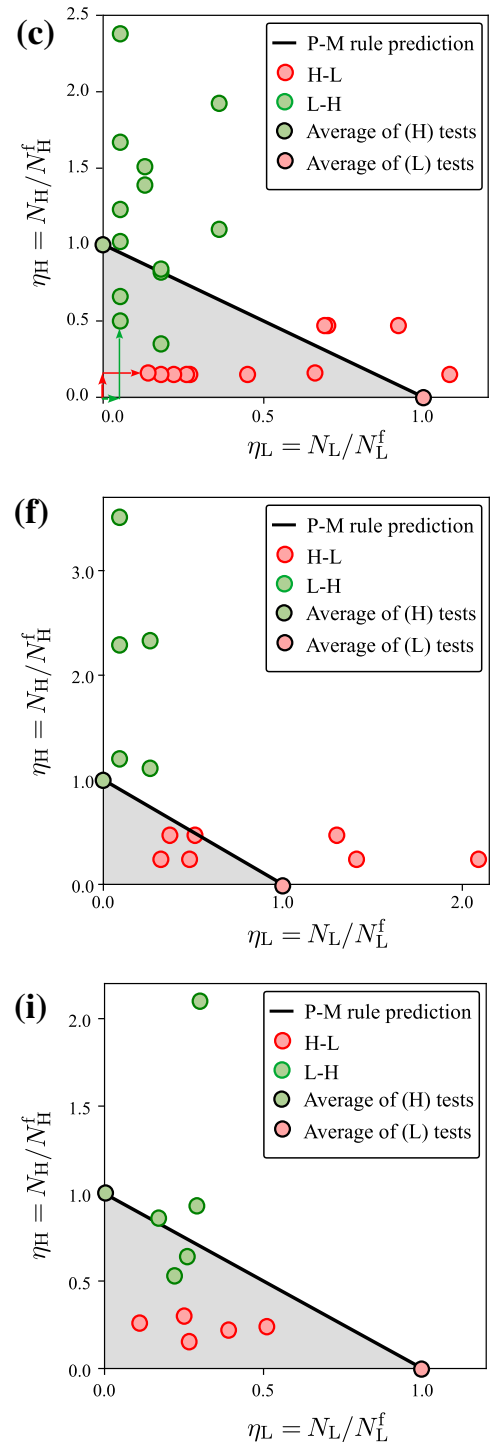

Fig. 7 Load sequence effect in concrete fatigue: a, b fatigue creep curves for $(\mathrm{H}-\mathrm{L})$ and $(\mathrm{L}-\mathrm{H})$ loading scenario respectively for concrete $\mathrm{C} 40$; $\mathbf{c}$ comparison with the predicted fatigue life of $\mathrm{P}-\mathrm{M}$ rule for concrete $\mathrm{C} 40 ; \mathbf{d}$, e fatigue creep curves for $(\mathrm{H}-\mathrm{L})$ and $(\mathrm{L}-\mathrm{H})$ loading scenario respectively for concrete $\mathrm{C} 80 ; \mathbf{f}$ comparison with the predicted fatigue life of $\mathrm{P}-\mathrm{M}$ rule for concrete $\mathrm{C} 80 ; \mathbf{g}, \mathbf{h}$ fatigue creep curves for $(\mathrm{H}-\mathrm{L})$ and $(\mathrm{L}-\mathrm{H})$ loading scenario respectively for concrete $\mathrm{C} 30$ by [18]; $\mathbf{i}$ comparison with the predicted fatigue life of $\mathrm{P}-\mathrm{M}$ rule for concrete $\mathrm{C} 30$ by [18]

one batch. However, the experiments were carried out over a long period of time, e.g. 326 days for C40. To account for the increasing strength during this period, the test dates were planned so that the sequence effect measured with scenario LS6 could be evaluated relative to the fatigue life measured with scenario LS5 on specimens of a comparable age.

\section{Phenomenology behind the sequence effect}

The summarized experimental data indicate that the (H-L) scenario accelerates the fatigue failure with respect to the $\mathrm{P}-\mathrm{M}$ linear scaling, while $(\mathrm{L}-\mathrm{H})$ scenario slows it down. Obviously, the kind of a loading sequence has a significant influence on the 
concrete fatigue life. However, its reproduction seems difficult due to the large scatter of the fatigue test results and due to the long duration and high energy consumption needed to perform tests with a sufficiently large sample. Moreover, the described trends seem to be relevant only for compressive fatigue. The sequence effect reported for bending tests shows a reverse trend with an earlier failure for $(\mathrm{L}-\mathrm{H})$ and later failure for (H-L) scenarios, respectively.

The theoretical explanation of the sequence effect can be provided based on the qualitative profiles of energy dissipation during the fatigue life. Consider the two curves in Fig. 8 showing the history of energy dissipation for the uniform cyclic loading $(\mathrm{H})$ and $(\mathrm{L})$ and for their ordered combinations (H-L) and (L-H). The energy dissipation for the loading $(\mathrm{H})$ is assumed higher than for (L) in agreement with experimental results presented, e.g. in [47, 71]. The left figure outlines a postulate that when the cyclic load changes from the higher level $(\mathrm{H})$ to the lower level $(\mathrm{L})$, the further dissipation profile of the $(\mathrm{H}-\mathrm{L})$ scenario can be predicted by switching to the branch observed for the uniform scenario (L). The switching is performed at the level of energy dissipation $\mathcal{G}_{\mathrm{H}}$ reached at the end of the first loading range $(\mathrm{H})$. In other words, the continuation point on branch $\eta_{\mathrm{L}}$ is associated with the same amount of dissipated energy, i.e. $\mathcal{G}_{\mathrm{L}}=\mathcal{G}_{\mathrm{H}}$. The resulting fatigue life of the $(\mathrm{H}-\mathrm{L})$ scenario can then be written as a sum

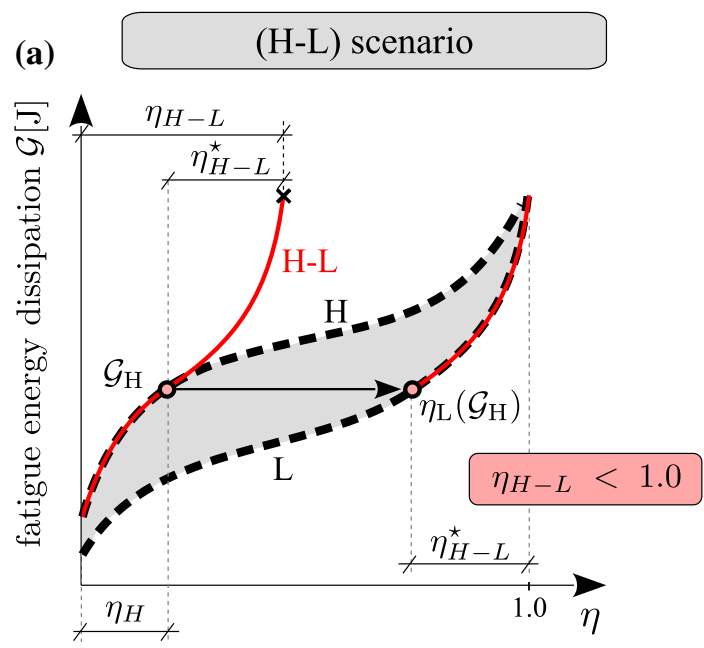

$\eta_{\mathrm{H}-\mathrm{L}}=\eta_{\mathrm{H}}+\eta_{\mathrm{H}-\mathrm{L}}^{\star}$

where $\eta_{\mathrm{H}-\mathrm{L}}^{\star}$ represents the residual fatigue life for the loading scenario (L) ahead of the point with energy dissipation equivalent to the value reached at the end of the first loading range $(\mathrm{H})$, i.e.

$\mathcal{G}_{L}\left(\eta_{L}\right)=\mathcal{G}_{H}\left(\eta_{H}\right)$

Since energy dissipation $\mathcal{G}$ is a monotonically increasing function, it can be inverted to deliver the fatigue lifetime consumed at a given level of energy dissipation

$\eta(\mathcal{G})=\mathcal{G}^{-1}(\eta)$.

Then, the residual fatigue life $\eta_{H-L}^{\star}$ in Eq. (6) can be expressed as

$\eta_{H-L}^{\star}=1-\eta_{L}\left(\mathcal{G}_{H}\right)$.

But is the proposed superposition of energy dissipation profiles really admissible? To answer this question, let us relate the energy dissipation $\mathcal{G}_{\mathrm{H}}$ due to the loading $(\mathrm{H})$ to the irreversible changes in the material structure of the tested specimen. The spatial distribution of these changes in each point $\boldsymbol{x}$ of the test specimen can be expressed in terms of inelastic state field variables $\boldsymbol{S}(\boldsymbol{x})$. To explain the sequence effect, it is not necessary to specify further details about the kind of the inelastic variables. However, to illustrate the phenomenon on a more concrete example, let us

(b)

\section{(L-H) scenario}

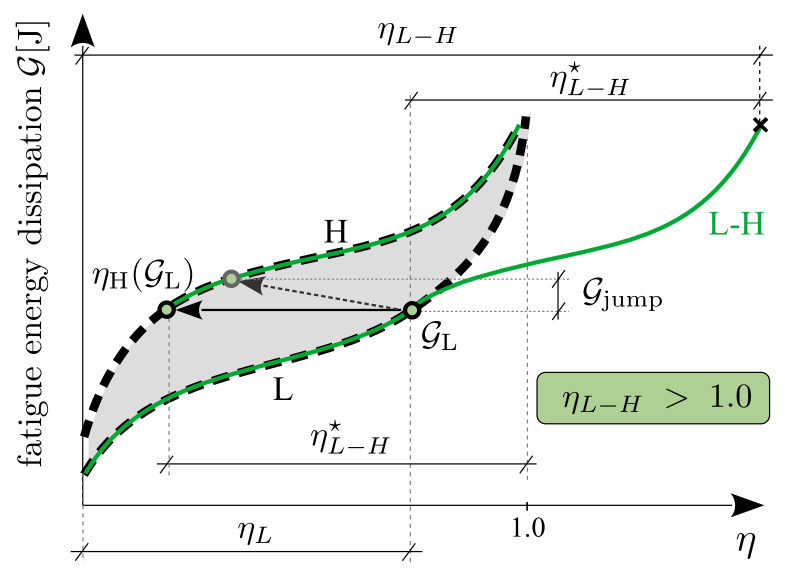

Fig. 8 Qualitative evolution of energy dissipation during fatigue life explaining the load sequence effect observed in compressive fatigue loading of concrete: $\mathbf{a}(\mathrm{H}-\mathrm{L})$ scenario; $\mathbf{b}(\mathrm{L}-\mathrm{H})$ scenario 
represent the inelastic material state by the fields of plastic strains and damage.

It can be argued that the above described superposition of energy dissipation profiles is admissible, if the state fields describing the changes within material structure $S_{\mathrm{H}}(x)$ and $S_{\mathrm{L}}(x)$ corresponding to the levels of energy dissipation $\mathcal{G}_{\mathrm{H}}$ and $\mathcal{G}_{\mathrm{L}}$ are equivalent in the whole domain of a specimen $\boldsymbol{x} \in \Omega$, i.e.

$$
S_{\mathrm{H}}(x) \approx S_{\mathrm{L}}(x) .
$$

This requirement is certainly not fulfilled if a test specimen exhibits strain localization, crack development, and propagation. However, in case of a pre-peak cyclic loading, this condition can be fulfilled. Indeed, recalling that the high-cycle fatigue loading is within a subcritical range and that according to Fig. $3 \mathrm{~d}-\mathrm{f}$, the dominating dissipative mechanism is related to plastic deformations within the material structure, a spatial uniformity of energy dissipation and of the inelastic state variables can be assumed. The fact, that the damage developing in the pre-peak regime is relatively small while the plastic strain grows rapidly suggests, that the pulsating plastic sliding along the aggregate interfaces can be regarded as the dominating source of energy dissipation [72-74]. Such a distributed dissipative mechanism does not exhibit localization, at least until the final stage of fatigue life. Therefore, it appears justified to assume that the changes within the material structure are evenly distributed over the specimen. In this case, the requirement for an approximately equivalent distribution of inelastic state variables expressed in equation Eq. (10) is fulfilled and an estimation of the fatigue life for a combined scenario based on the superposition of the energy dissipation curves according to equations Eqs. (6) and (9) becomes possible.

With the present superposition rule, we might now define complex loading scenarios within the $\mathcal{G}(\eta)$ domain and directly predict a combined fatigue life, e.g. for $(\mathrm{H}-\mathrm{L}),(\mathrm{L}-\mathrm{H})$ or even more complex loading histories. However, an additional issue to be considered for the $(\mathrm{L}-\mathrm{H})$ scenario is indicated in Fig. $8 \mathrm{~b}$. While a load reduction (H-L) can be assumed purely elastic with zero energy dissipation, the switch from (L) to $(\mathrm{H})$ cycling level can be associated with energy dissipation during the monotonically increasing loading. To relate the amount of energy dissipation due to this load increase to the dissipation due to cyclic loading, we will take a closer look at Fig. 5, which shows the results obtained for the step-wise increasing loading scenario LS3. As no significant reduction of stiffness can be recognized during the load increase, the amount of dissipated energy during the switch can be considered relatively small. In general we can assume that in the pre-peak load range, the energy dissipation within a large number of hysteretic loops dominates in comparison to the amount of energy dissipation due to the one-time load switch between (L) and (H) levels.

Finally, under the given assumptions the lifetime of the combined loading scenarios $(\mathrm{H}-\mathrm{L})$ and $(\mathrm{L}-\mathrm{H})$ can be directly evaluated using Eqs. (6) and (9). Moreover, the energy based superposition provides a transparent explanation of the sequence effect observed in the performed test series. An (H-L) scenario depicted Fig. $8 \mathrm{~b}$ must necessarily lead to the reduction of the fatigue life compared to the $\mathrm{P}-\mathrm{M}$ rule. On the other hand, an L-H scenario shown in Fig. 8b results in a longer lifetime compared to the $\mathrm{P}-\mathrm{M}$ superposition rule.

Even though the strain development for the high strength concrete is quantitatively different from the normal concrete, the fatigue creep curves remain qualitatively similar. Also, the sequence effect follows the same trend. Considering a high-strength concrete, an additional local dissipative mechanism represented by aggregate cracking can effect the response in the range of the ultimate failure. The quantitative conclusion, however, can only be provided with a more detailed experimental-numerical analysis of the interaction between the local dissipative effects.

It must be stressed, however, that the described explanation of the sequence effect is not valid for problems with macroscopic stress redistribution and strain localization within the volume of a specimen. For test setups with propagation of tensile cracks in the bending test or debonding in the pull-out test, the required simultaneous equivalence of dissipated energy Eq. (7) and of inelastic state variable distribution over the entire volume Eq. (10) is not fulfilled. Therefore, experimental observations reporting a reverse sequence effect compared to the results presented here for compressive concrete fatigue cannot be predicted by the presented energetic consideration. Their detailed interpretation is only possible using models accounting for the evolution of the inelastic state field during the cyclic loading 
process. However, we consider it important to communicate the observation in this qualitative and simple form as it suggests, that the sequence effect measured in a standard laboratory compressive test exhibits a significantly different phenomenology from the behavior occurring in general in-situ configurations.

Returning to the compressive fatigue loading we can summarize, that both the theoretical energetic analysis and the presented experimental results reveal that the sequence effect leads to significant deviations of the real fatigue life from the commonly used $\mathrm{P}-\mathrm{M}$ rule.

\section{Assessment rules and sequence effect}

Several engineering assessment rules taking the sequence effect in concrete fatigue behavior under compression into account already exist. They are briefly presented and validated based on the presented test results.

\subsection{Linear damage accumulation $\mathrm{P}-\mathrm{M}$ rule}

The well-known $\mathrm{P}-\mathrm{M}$ rule applied in the current design codes assumes a linear damage accumulation as already described in Sec. 1. Even though, the validity of this rule to be applied for concrete compressive fatigue behavior has been examined and discussed in Sec. 3.6, this rule provides the baseline for comparison of existing alternative rules.

\subsection{Nonlinear damage accumulation rules}

Nonlinear damage rule by Shah Based on the observable shape of the damage growth in concrete during fatigue life presented by Holmen et al. [18], a nonlinear damage rule has been proposed by Shah [33] as follows

$$
\omega=a\left(\frac{N}{N^{\mathrm{f}}}\right)^{3}+b\left(\frac{N}{N^{\mathrm{f}}}\right)^{2}+c\left(\frac{N}{N^{\mathrm{f}}}\right),
$$

where $a, b$ and $c$ are constants to be determined from the experimentally observed shape of the damage growth during fatigue life. In the present comparison, the values specified in [33] are taken as $a=1.14, b=-2.40, c=2.26$. For the prediction of the fatigue life under varying loading ranges, the cumulative damage rule has been proposed in the form

$$
\eta=a \sum\left(\frac{N_{\mathrm{i}}}{N_{\mathrm{i}}^{\mathrm{f}}}\right)^{3}+b \sum\left(\frac{N_{\mathrm{i}}}{N_{\mathrm{i}}^{\mathrm{f}}}\right)^{2}+c \sum\left(\frac{N_{\mathrm{i}}}{N_{\mathrm{i}}^{\mathrm{f}}}\right)=1 .
$$

The nonlinear damage evolution delivered by this rule is depicted as a dashed green curve in Fig. 9a.

Nonlinear damage rule by Gryzbowski Another nonlinear damage rule has been proposed by Grzybowski and Meyer [34]. In this rule, the damage growth is dependent on the loading range defined by the upper stress level $S^{\max }$ as follows

$$
\omega= \begin{cases}\left(1.7-S^{\max }\right)\left(\frac{N}{N^{\mathrm{f}}}\right), & \text { for }\left(\frac{N}{N^{\mathrm{f}}}\right) \leq 0.6 \\ \left(\frac{N}{N^{\mathrm{f}}}\right)^{1.6 S^{\max },} & \text { for }\left(\frac{N}{N^{\mathrm{f}}}\right)>0.6 .\end{cases}
$$

The nonlinear damage evolution curves obtained using this rule are depicted in Fig. 9a for individual loading levels as dashed red curves.

\subsection{Enhanced P-M assessment rule}

A refined engineering rule has been recently suggested by the authors [35]. The rule has been derived based on a combined numerical and experimental investigations of the loading sequence effect [75-77]. This rule can be considered as an enhanced $\mathrm{P}-\mathrm{M}$ rule, evaluating the consumed fatigue life under a loading scenario consisting of $n$ varying loading ranges in the form

$$
\eta=\sum_{i=1}^{n} \eta_{i}+\sum_{i=1}^{n-1} \Delta \eta_{i}
$$

Similarly to the $\mathrm{P}-\mathrm{M}$ rule, the fatigue failure occurs when the cumulative fatigue damage $\eta=1$. The consumed fatigue life of the $i$-th loading level applied for the whole lifetime is given as $\eta_{i}=N_{i} / N_{i}^{\mathrm{f}}$. The extension of the $\mathrm{P}-\mathrm{M}$ rule is introduced by the correction terms $\Delta \eta_{i}$ reflecting the effect of a change between the cyclic loading ranges $i$ and $i+1$ on the response of a compressive specimen. The correction term $\Delta \eta_{i}$ is provided in form of a response function of the parameters of the load jump between two consecutive ranges 
(a)

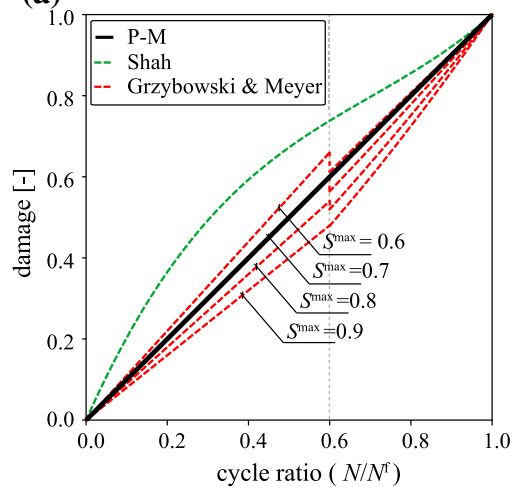

(b)

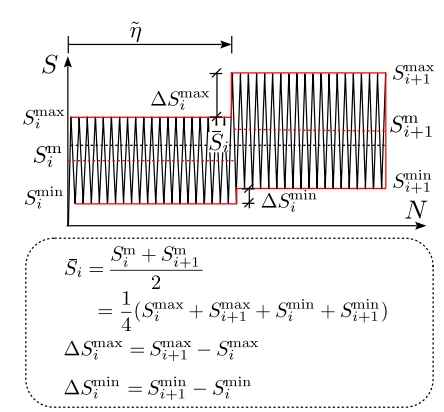

(c)

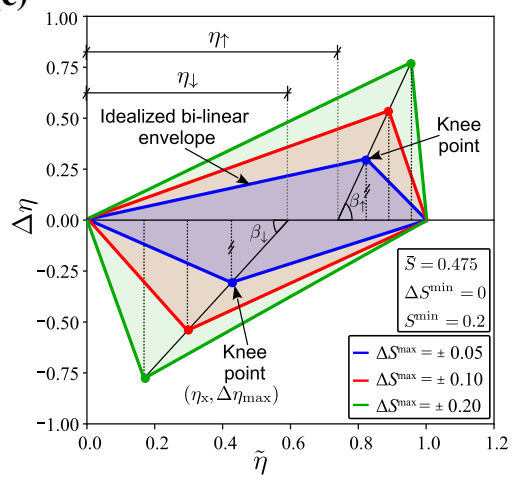

Fig. 9 Engineering assessment rules: a fatigue damage accumulation rules; $\mathbf{b}$ illustration of the loading parameters; $\mathbf{c}$ idealized bilinear envelope of the enhanced $\mathrm{P}-\mathrm{M}$ assessment rule of $\Delta \eta$ for different values of the loading jump $\Delta S^{\text {max }}$

$$
\Delta \eta_{i} \stackrel{\text { def }}{=} \mathcal{R}\left(\overline{S_{i}}, \Delta S_{i}^{\max }, \Delta S_{i}^{\min }, \tilde{\eta}_{i}\right)
$$

The individual parameters of the response function have the following meaning (Fig. 9b):

- The mean load level $\bar{S}_{i}$ within the two loading ranges is given as $\bar{S}_{i}=\left(S_{i}^{\mathrm{m}}+S_{i+1}^{\mathrm{m}}\right) / 2$ where $S_{i}^{\mathrm{m}}, S_{i+1}^{\mathrm{m}}$ are the mean values of the individual loading ranges $i, i+1$ expressed as $S_{i}^{\mathrm{m}}=$ $\left(S_{i}^{\max }+S_{i}^{\min }\right) / 2 \quad$ and $\quad S_{i+1}^{\mathrm{m}}=\left(S_{i+1}^{\max }+S_{i+1}^{\min }\right) / 2$, respectively.

- The jumps $\Delta S_{i}^{\max }$ and $\Delta S_{i}^{\min }$ between the upper and lower bounds of the two subsequent loading ranges $S_{i}^{\max }, S_{i+1}^{\max }$ and $S_{i}^{\min }, S_{i+1}^{\min }$ are introduced as $\Delta S_{i}^{\max }=$ $S_{i+1}^{\max }-S_{i}^{\min }$ and $\Delta S_{i}^{\min }=S_{i+1}^{\min }-S_{i}^{\min }$, respectively.

- The parameter $\tilde{\eta}_{i}$ represents the cumulatively consumed fatigue life prior to the loading jump between the loading ranges $i$ and $i+1$.

The correction term $\Delta \eta_{i}$ is given as:

$$
\Delta \eta_{i}= \begin{cases}\Delta \eta_{\max }\left(1-\frac{\eta_{\mathrm{x}}-\tilde{\eta}_{i}}{\eta_{\mathrm{x}}}\right), & 0<\tilde{\eta}_{i} \leq \eta_{\mathrm{x}} \\ \Delta \eta_{\max }\left(\frac{\tilde{\eta}_{i}-1}{\eta_{\mathrm{x}}-1}\right), & \eta_{\mathrm{x}}<\tilde{\eta}_{i}<1,\end{cases}
$$

where $\left(\eta_{\mathrm{x}}, \Delta \eta_{\max }\right)$ represents the position of knee points of the response function (Fig. 9c). The vertical position of the knee point $\Delta \eta_{\max }$ is given as $\Delta \eta_{\max }\left(\bar{S}, \Delta S^{\max }\right)=\left[f_{1}\left(\Delta S^{\max }\right)+f_{2}(\bar{S})\right] \operatorname{sign}\left(\Delta S^{\max }\right)$

with

$$
f_{1}\left(\Delta S^{\max }\right)=A\left(\Delta S^{\max }\right)^{2}+B \Delta S^{\max } \operatorname{sign}\left(\Delta S^{\max }\right)
$$

$f_{2}(\bar{S})=C(0.475-\bar{S})$.

Here, $A, B, C$ are material parameters identified using the numerical simulation of the fatigue behavior under two loading ranges and, can be taken as

$A=-10.66, B=6.1, C=2.0$.

The horizontal position of the knee point $\eta_{\mathrm{x}}$ is given as $\eta_{\mathrm{x}}= \begin{cases}\eta_{\uparrow}+\Delta \eta_{\max } / \tan \left(\beta_{\uparrow}\right), & \Delta \eta_{\max }>0 \\ \eta_{\downarrow}+\Delta \eta_{\max } / \tan \left(\beta_{\downarrow}\right), & \Delta \eta_{\max }<0 .\end{cases}$

Here, $\eta_{\uparrow}, \beta_{\uparrow}, \eta_{\downarrow}, \beta_{\downarrow}$ are material parameters that has been identified as

$\eta_{\uparrow}=0.74, \beta_{\uparrow},=74.7^{\circ}, \eta_{\downarrow}=0.59, \beta_{\downarrow}=60.5^{\circ}$.

The enhanced P-M rule proposed in Ref. [35] has been formulated based on a combined numerical- experimental methodology employing an anisotropic fatigue damage model. The numerical model and the obtained rule can be calibrated based on the experimental data conducted with a prescribed loading frequency see [35]. A direct influence of loading frequency has not yet been included in the proposed rule due to the lack of sufficient experimental data on the loading sequence effect. On the other hand, the proposed theoretical interpretation of the loading sequence effect explaining the qualitative trends discussed in Sec. 4 is applicable to a wide range of loading frequency, and further refined rule can be derived based on the obtained data with constant amplitudes. 


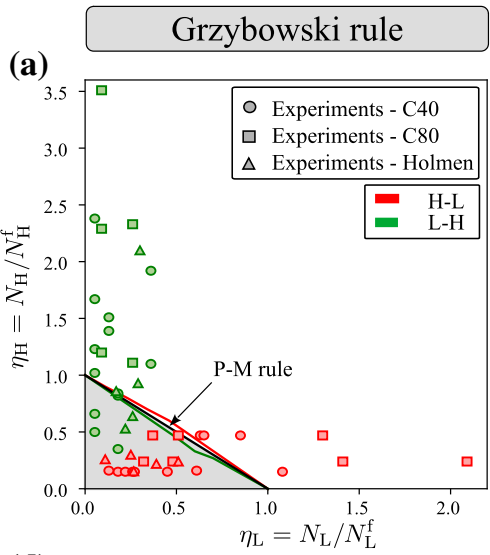

(d)

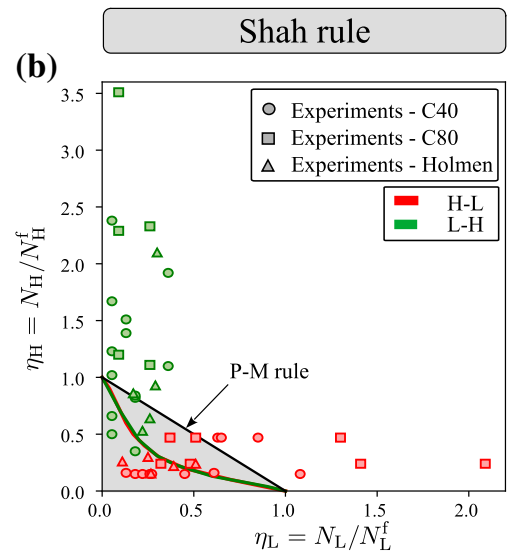

(e)

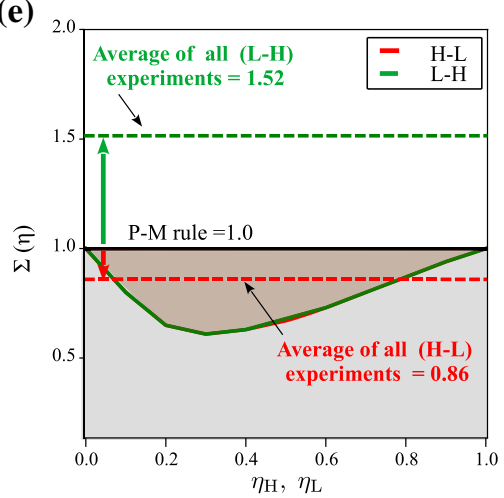

Enhanced P-M rule

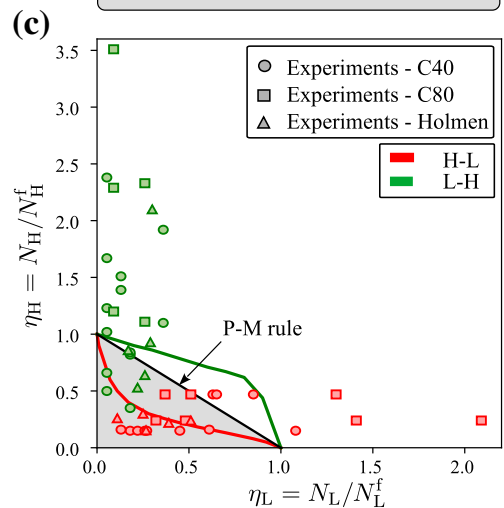

(f)

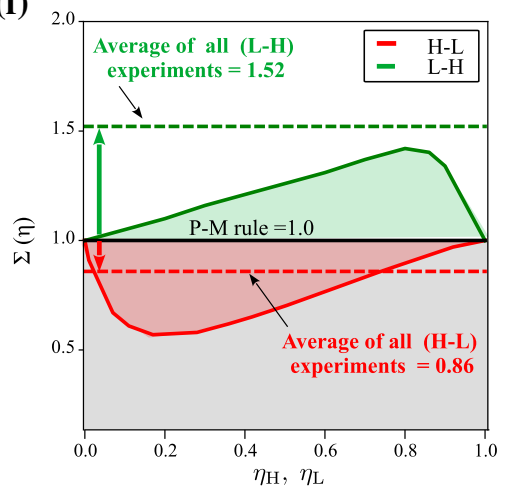

Fig. 10 Evaluation of the assessment rules based on the experimental results: a, d Grzybowski rule; b, e Shah rule; c, f Enhanced P-M rule

\subsection{Evaluation of the fatigue assessment rules}

The described assessment rules are compared in Fig. 10. The diagrams in the first row Fig. 10a-c present the results of all experiments with $(\mathrm{H}-\mathrm{L})$ and $(\mathrm{L}-\mathrm{H})$ loading scenarios plotted in terms of the consumed fatigue life diagrams similar to Fig. 7c. The predictions of $\mathrm{P}-\mathrm{M}$ rule as well as the other studied rules are included. It can be observed from the experimental results that the majority of the $(\mathrm{L}-\mathrm{H})$ tests fails with $\sum \eta>1.0$ i.e. above the $\mathrm{P}-\mathrm{M}$ rule prediction, whereas the majority of the $(\mathrm{H}-\mathrm{L})$ tests fails with $\sum \eta<1.0$ i.e. below the $\mathrm{P}-\mathrm{M}$ rule prediction.

In the second row of Fig. 10 different view to the test results is provided with the consumed fatigue life of the first applied loading range displayed on the horizontal axis, i.e. $\eta_{\mathrm{H}}$ for $(\mathrm{H}-\mathrm{L})$ scenario and $\eta_{\mathrm{L}}$ for $(\mathrm{L}-\mathrm{H})$ scenario. The vertical axis represents the sum of the consumed fatigue life for both loading ranges $\sum \eta=\eta_{\mathrm{H}}+\eta_{\mathrm{L}}$. The averages of all experimental results are plotted as a green dashed line for $(\mathrm{L}-\mathrm{H})$ scenario, and red dashed line for $(\mathrm{H}-\mathrm{L})$ scenario. The average of all (H-L) tests presented in Sec. 3.6 was $\sum \eta=0.86$, whereas the average of all $(\mathrm{L}-\mathrm{H})$ tests was $\sum \eta=1.52$.

Apparently, the nonlinear damage accumulation rule proposed by Shah shows an equal reduction of the fatigue life for both loading sequences $(\mathrm{H}-\mathrm{L})$ and $(\mathrm{L}-$ H) see Fig. 10b, e. This implies that this rule does not account for the loading sequence effect and can lead to a conservative prediction for some scenarios. On the other hand, the results obtained by the rule proposed by Grzybowski show lower sensitivity to the loading sequence and delivers a prediction close to the $\mathrm{P}-\mathrm{M}$ rule as depicted in Fig. 10a, d.

The results obtained from the proposed enhanced $\mathrm{P}-\mathrm{M}$ rule Fig. 10c, f show trends that are consistent with those observed in the presented experiments and in the results published in literature [18]. This rule takes the effect of the loading sequence into account in more realistic way than the other two available rules. 
Due to the huge scatter of the experimental result, limited range of tested levels, and range of prescribed consumed fatigue life in the first load period of the test, i.e. $\eta_{\mathrm{L}}, \eta_{\mathrm{H}}$, a quantitative validation is not possible. Still, the qualitative comparison of the three considered rules can be regarded as a stepping stone for a broader theoretical and experimental analysis. Further experimental investigation with advanced and physically consistent representation of the fatigue phenomenology is required to provide a quantitative validation of the considered assessment rules on a broad scale of stress configurations.

\section{Conclusions}

Even though some experimental studies performed in the past indicated the existence of a load sequence effect in the concrete fatigue behavior, contradicting trends have been reported for compressive and tensile loads. The load sequence effect observed in compression by Holmen [18] and Petkovic et al. [19] indicating that the well-known $\mathrm{P}-\mathrm{M}$ rule does not realistically predict the fatigue life under variable amplitudes has been confirmed by the present experimental study. The test results reveal unsafe prediction by the $\mathrm{P}-\mathrm{M}$ rule for $(\mathrm{H}-\mathrm{L})$ load sequence and a conservative prediction for the $(\mathrm{L}-\mathrm{H})$ load sequence.

However, due to the inevitably large scatter and the high costs of fatigue tests, only relatively small test series can be carried out, which makes it difficult to identify and reproduce generally valid phenomena of fatigue behavior. To substantiate the experimentally observed sequence effect in compression we provide a theoretical analysis considering the evolution of energy dissipation during the fatigue loading. This analysis shows that the observed difference between fatigue life for switched load sequences $(\mathrm{H}-\mathrm{L})$ and $(\mathrm{L}-$ $\mathrm{H}$ ) occurs only if energy dissipates evenly within the volume of a specimen without an early damage localization. This analysis also offers an explanation for the fact that in tests with damage localization, such as the fatigue bending test, reverse sequence effect is observed.

The results obtained were used to validate the existing assessment rules, which take into account the sequence effect in the compressive fatigue behavior of concrete. This validation has shown that the enhanced $\mathrm{P}-\mathrm{M}$ rule recently proposed by the authors is capable of predicting the trends in lifetime changes due to the sequence effect. This validation and the energy-based explanation of the sequence effect show the potential for further development of models that can realistically predict the fatigue life of concrete structures under generally variable fatigue loading scenarios.

Acknowledgements The work was supported by the Federal Ministry for Economic Affairs and Energy, Germany (BMWi), in the framework of the joint project (WinConFat), (Project No: 0324016C), and by the Deutsche Forschungsgemeinschaft (DFG, German Research Foundation), in the scope of the joint Project (CumFatiCon) "Fatigue of structural concrete driven by a cumulative measure of shear strain." (Project No. 412131890). This support is gratefully acknowledged.

Funding Open Access funding enabled and organized by Projekt DEAL.

\section{Declarations}

Conflict of interest The authors declare that they have no conflict of interest.

Open Access This article is licensed under a Creative Commons Attribution 4.0 International License, which permits use, sharing, adaptation, distribution and reproduction in any medium or format, as long as you give appropriate credit to the original author(s) and the source, provide a link to the Creative Commons licence, and indicate if changes were made. The images or other third party material in this article are included in the article's Creative Commons licence, unless indicated otherwise in a credit line to the material. If material is not included in the article's Creative Commons licence and your intended use is not permitted by statutory regulation or exceeds the permitted use, you will need to obtain permission directly from the copyright holder. To view a copy of this licence, visit http://creativecommons.org/licenses/by/4.0/.

\section{References}

1. Zhu S-P, Hao Y-Z, de Oliveira Correia JA, Lesiuk G, de Jesus AM (2018) Nonlinear fatigue damage accumulation and life prediction of metals: a comparative study. Fatigue Fract Eng Mater Struct 42(6):1271-1282. https://doi.org/10. 1111/ffe. 12937

2. Aghoury IE, Galal K (2013) A fatigue stress-life damage accumulation model for variable amplitude fatigue loading based on virtual target life. Eng Struct 52:621-628. https:// doi.org/10.1016/j.engstruct.2013.03.001

3. Baptista C, Reis A, Nussbaumer A (2017) Probabilistic s-n curves for constant and variable amplitude, fatigue assessment of welded joints by modern concepts. Int J Fatigue 101:312-327. https://doi.org/10.1016/j.ijfatigue.2017.01. 022 
4. Fisher JW (1993) Resistance of welded details under variable amplitude long-life fatigue loading, vol 354. Transportation Research Board

5. Teworte F, Herbrand M, Hegger J (2015) Structural assessment of concrete bridges in Germany-shear resistance under static and fatigue loading. Struct Eng Int 25(3):266-274. 101686615X14210663188411

6. Tepfers R, Fridén C, Georgsson L (1977) A study of the applicability to the fatigue of concrete of the palmgrenminer partial damage hypothesis. Mag Concr Res 29(100):123-130. https://doi.org/10.1680/macr.1977.29. 100.123

7. Lenschow R (1980) Long term random dynamic loading of concrete structures. Matér Constr 13(3):274-278. https:// doi.org/10.1007/BF02474050

8. Chen X, Bu J, Fan X, Lu J, Xu L (2017) Effect of loading frequency and stress level on low cycle fatigue behavior of plain concrete in direct tension. Constr Build Mater 133:367-375. https://doi.org/10.1520/JTE20180348

9. Slowik V, Plizzari GA, Saouma VE (1996) Fracture of concrete under variable amplitude fatigue loading. Mater J 93(3):272-283. https://doi.org/10.14359/9812

10. Lu J, Fan X, Li S, Shi D, Chen X (2019) Influence of loading sequence on low cycle fatigue behavior of normal weight concrete under direct tension. J Test Eval 47:6. https://doi. org/10.1520/JTE20180348

11. Kirane K, Bažant ZP (2015) Microplane damage model for fatigue of quasibrittle materials: Sub-critical crack growth, lifetime and residual strength. Int J Fatigue 70:93-105. https://doi.org/10.1016/j.ijfatigue.2014.08.012

12. fib Model Code 2010. International Federation for Structural Concrete, fib model code for concrete structures. https://doi.org/10.1002/9783433604090

13. EN-1992-2 (2005) Eurocode 2: Design of concrete structures, part 2: concrete bridges-design and detailing rules, European Committee for Standardisation

14. EN-1993-2 (2006) Eurocode 3, design of steel structures, part 2: steel bridges. European Committee for Standardisation

15. EN-1993-1-9 (2005) Eurocode 3, Design of steel structures, Part 1-9: Fatigue, European Committee for Standardisation

16. Palmgren A (1924) Die Lebensdauer von Kugellagern (durability of ball bearings). ZDVD 68:339

17. Miner M et al (1945) Cumulative fatigue damage. J Appl Mech 12(3):A159-A164

18. Holmen JO (1982) Fatigue of concrete by constant and variable amplitude loading. ACI J 75:71-110. https://doi. org/10.14359/6402

19. Petkovic G, Lenschow R, Stemland H, Rosseland S (1990) Fatigue of high-strength concrete. Spec Pub 121:505-526. https://doi.org/10.14359/3740

20. Bennett E (1980) Fatigue of plain concrete in compression under varying sequences of two-level programme loading. Int J Fatigue 2(4):171-175. https://doi.org/10.1016/01421123(80)90045-6

21. Klausen D (1978) Festigkeit und Schädigung von Beton bei häufig wiederholter Beanspruchung. https://trid.trb.org/ view/1044257

22. Hegger J, Roggendorf T, Goralski C, Roeser W (2012) Ermüdungsverhalten von Beton unter zyklischer
Beanspruchung aus dem Betrieb von Windkraftanlagen.DIBt - Forschungsvorhaben, $\mathrm{H}+\mathrm{P}$ Ingenieure GmbH\&co. KG und Lehrstuhl und Institut für Massivbau der RWTH Aachen

23. Roggendorf T, Goralski C (2014) Ermüdungsverhalten von Beton unter zyklischer Beanspruchung aus dem Betrieb von Windenergieanlagen. Beton-und Stahlbetonbau 109(11):824-828. https://doi.org/10.1002/best.201400064

24. Hilsdorf HK et al (1966) Fatigue strength of concrete under varying flexural stresses. J Proc 63:1059-1076. https://doi. org/10.14359/7662

25. Baktheer A, Chudoba R (2018) Pressure-sensitive bond fatigue model with damage evolution driven by cumulative slip: thermodynamic formulation and applications to steeland frp-concrete bond. Int J Fatigue 113:277-289. https:// doi.org/10.1016/j.ijfatigue.2018.04.020

26. Baktheer A, Chudoba R (2018) Modeling of bond fatigue in reinforced concrete based on cumulative measure of slip. In: Computational modelling of concrete structures, EURO-C 2018. CRC Press, pp 767-776. https://doi.org/10.1201/ 9781315182964-90

27. Fatemi A, Yang L (1998) Cumulative fatigue damage and life prediction theories: a survey of the state of the art for homogeneous materials. Int J Fatigue 20(1):9-34. https:// doi.org/10.1016/S0142-1123(97)00081-9

28. Huffman P, Beckman S (2013) A non-linear damage accumulation fatigue model for predicting strain life at variable amplitude loadings based on constant amplitude fatigue data. Int J Fatigue 48:165-169. https://doi.org/10. 1016/j.ijfatigue.2012.10.016

29. Benkabouche S, Guechichi H, Amrouche A, Benkhettab M (2015) A modified nonlinear fatigue damage accumulation model under multiaxial variable amplitude loading. Int $\mathbf{J}$ Mech Sci 100:180-194. https://doi.org/10.1016/j.ijmecsci. 2015.06.016

30. Halford GR (1997) Cumulative fatigue damage modelingcrack nucleation and early growth. Int $\mathrm{J}$ Fatigue 19(93):253-260. https://doi.org/10.1016/S01421123(97)00048-0

31. Kujawski D, Ellyin F (1984) A cumulative damage theory for fatigue crack initiation and propagation. Int $\mathrm{J}$ Fatigue 6(2):83-88. https://doi.org/10.1016/0142-1123(84)90017-3

32. Weinacht D, Socie D (1987) Fatigue damage accumulation in grey cast iron. Int J Fatigue 9(2):79-86. https://doi.org/ 10.1016/0142-1123(87)90048-X

33. Shah S (1984) Predictions of cumulative damage for concrete and reinforced concrete. Matér Constr 17(1):65-68. https://doi.org/10.1007/BF02474059

34. Grzybowski M, Meyer C (1993) Damage accumulation in concrete with and without fiber reinforcement. Mater $\mathbf{J}$ 90(6):594-604. https://doi.org/10.14359/4438

35. Baktheer A, Hegger J, Chudoba R (2019) Enhanced assessment rule for concrete fatigue under compression considering the nonlinear effect of loading sequence. Int $\mathbf{J}$ Fatigue 126:130-142. https://doi.org/10.1016/j.ijfatigue. 2019.04.027

36. Oh BH (1991) Cumulative damage theory of concrete under variable-amplitude fatigue loadings. Mater J 88(1):41-48. https://doi.org/10.14359/2357

37. Heek P, Ahrens MA, Mark P (2017) Incremental-iterative model for time-variant analysis of sfrc subjected to flexural 
fatigue. Mater Struct 50(1):62. https://doi.org/10.1617/ s11527-016-0928-Z

38. Heek P, Mark P (2019) Multiaxial and variable amplitude fatigue of concrete. Civ Eng Des 1(3-4):87-96. https://doi. org/10.1002/cend.201900010

39. Deutscher M, Tran NL, Scheerer S (2020) Experimental investigations on temperature generation and release of ultra-high performance concrete during fatigue tests. Appl Sci 10(17):5845. https://doi.org/10.3390/app10175845

40. Myrtja E, Soudier J, Prat E, Chaouche M (2020) Fatigue deterioration mechanisms of high-strength grout in compression. Constr Build Mater. https://doi.org/10.1016/j. conbuildmat.2020.121387

41. Morris K (2011) What is hysteresis? Appl Mech Rev 64(5):050801. https://doi.org/10.1115/1.4007112

42. Mayergoyz I (1986) Mathematical models of hysteresis. IEEE Trans Magn 22(5):603-608. https://doi.org/10.1115/ 1.4007112

43. Thiele M, Petryna Y, Rogge A Experimental investigation of damage evolution in concrete under high-cycle fatigue. In: 9th International conference on fracture mechanics of concrete and concrete structures-FraMCoS-9. https://doi. org/10.21012/FC9.302

44. Do M, Chaallal O, Aitcin P (1993) Fatigue behavior of high performance concrete. J Mater Civ Eng 5(1):96-111. https://doi.org/10.1061/(ASCE)0899-1561(1993)5:1(96)

45. Xiao J, Li H, Yang Z (2013) Fatigue behavior of recycled aggregate concrete under compression and bending cyclic loadings. In: 25th Anniversary session for ACI 228building on the Past for the Future of NDT of Concrete. Construction and Building Materials, vol 38. pp 681-688. https://doi.org/10.1016/j.conbuildmat.2012.09.024

46. Seweryn A, Buczyński A, Szusta J (2008) Damage accumulation model for low cycle fatigue. Int $\mathrm{J}$ Fatigue 30(4):756-765. https://doi.org/10.1016/j.ijfatigue.2007.03. 019

47. Bode M, Marx S, Vogel A, Völker C Dissipationsenergie bei Ermüdungsversuchen an Betonprobekörpern, Betonund Stahlbetonbau. https://doi.org/10.1002/best.201900004

48. Kim J-K, Kim Y-Y (1996) Experimental study of the fatigue behavior of high strength concrete. Cem Concr Res 26(10):1513-1523. https://doi.org/10.1016/00088846(96)00151-2

49. Rossi P, Parant E (2008) Damage mechanisms analysis of a multi-scale fibre reinforced cement-based composite subjected to impact and fatigue loading conditions. Cem Concr Res 38(3):413-421. https://doi.org/10.1016/j.cemconres. 2007.09.002

50. ClaSSen M, Gallwoszus J (2016) Concrete fatigue in composite dowels. Struct Concr 17(1):63-73. https://doi. org/10.1002/suco.201400120

51. Christou G, Hegger J, Classen M (2020) Fatigue of clothoid shaped rib shear connectors. J Constr Steel Res 171:106133. https://doi.org/10.1016/j.jcsr.2020.106133

52. Hillebrand M, Hegger J (2020) Fatigue testing of shear reinforcement in prestressed concrete t-beams of bridges. Appl Sci 10(16):5560. https://doi.org/10.3390/ app 10165560

53. Holmen J (1984) Fatigue design evaluation of offshore concrete structures. Matér Constr 17(1):39-42. https://doi. org/10.1007/BF02473210
54. Wang H, Song Y (2011) Fatigue capacity of plain concrete under fatigue loading with constant confined stress. Mater Struct 44(1):253-262. https://doi.org/10.1617/s11527-0109624-6

55. Hsu TT (1981) Fatigue of plain concrete. J Proc 78:292-305. https://doi.org/10.1115/1.3656900

56. Hümme J, Haar C, Lohaus L, Marx S (2015) Fatigue behaviour of a normal-strength concrete-number of cycles to failure and strain development. Struct Concr 17(4):637-645. https://doi.org/10.1002/suco.201500139

57. Lohaus L, Oneschkow N, Wefer M (2012) Design model for the fatigue behaviour of normal-strength, high-strength and ultra-high-strength concrete. Struct Concr 13(3):182-192. https://doi.org/10.1002/suco.201100054

58. Wieneke K, van Elten L, ClaSSen M, Hegger J (2017) Ermüdung von Elementdecken mit Gitterträgern. Betonund Stahlbetonbau 112(11):723-733. https://doi.org/10. 1002/best.201700047

59. Spartali H, Chudoba R (2020) high-cycle-fatigue-tool v1.0.0. https://doi.org/10.5281/zenodo.3603817

60. Oneschkow N (2016) Fatigue behaviour of high-strength concrete with respect to strain and stiffness. Int J Fatigue 87:38-49. https://doi.org/10.1016/j.ijfatigue.2016.01.008

61. Raue E, Tartsch E (2005) Experimental results of fatigue and sustained load tests on autoclaved aerated concrete. J Civ Eng Manag 11(2):121-127. https://doi.org/10.3846/ 13923730.2005.9636341

62. Fan Z, Sun Y (2020) A study on fatigue behaviors of concrete under uniaxial compression: testing, analysis, and simulation. J Test Eval. https://doi.org/10.1520/ JTE20190900

63. Zanuy C, Albajar L, de la Fuente P (2011) The fatigue process of concrete and its structural influence. Mater Constr 61(303):385-399. https://doi.org/10.3989/mc.2010. 54609

64. Breitenbücher R, Ibuk H (2006) Experimentally based investigations on the degradation-process of concrete under cyclic load. Mater Struct 39(7):717-724. https://doi.org/10. 1617/s11527-006-9097-9

65. Caner FC, Bažant ZP (2013) Microplane model m7 for plain concrete. ii. Calibration and verification. J Eng Mech 139(12):1724-1735. https://doi.org/10.1061/(ASCE)EM. 1943-7889.0000571

66. Lemaitre J (2012) A course on damage mechanics. Springer, Berlin. https://doi.org/10.1007/978-3-642-18255-6

67. Lemaitre J, Desmorat R (2005) Engineering damage mechanics: ductile, creep, fatigue and brittle failures. Springer, Berlin

68. Mu B, Shah SP (2005) Fatigue behavior of concrete subjected to biaxial loading in the compression region. Mater Struct 38(3):289-298. https://doi.org/10.1007/BF02479293

69. Osorio E, Bairán JM, Marí AR (2013) Lateral behavior of concrete under uniaxial compressive cyclic loading. Mater Struct 46(5):709-724. https://doi.org/10.1617/s11527-0129928-9

70. Yankelevsky DZ, Reinhardt HW (1987) Model for cyclic compressive behavior of concrete. J Struct Eng 113(2):228-240. https://doi.org/10.1061/(ASCE)07339445(1987)113:2(228) 
71. Bode M, Marx S (2020) Energetic damage analysis regarding the fatigue of concrete. Struct Concr. https://doi. org/10.1002/suco.202000416

72. Li J, Gao X, Zhang P (2007) Experimental investigation on the bond of reinforcing bars in high performance concrete under cyclic loading. Mater Struct 40(10):1027-1044. https://doi.org/10.1617/s11527-006-9201-1

73. Camps B, Baktheer A, Hegger J, Chudoba R (2018) Experimental characterization of bond fatigue using beamend tests with push-in loading. In: Multidisciplinary digital publishing institute proceedings, vol. 2, p 417. https://doi. org/10.3390/ICEM18-05270

74. Huang L, Ye H, Chu S, Xu L, Chi Y (2019) Stochastic damage model for bond stress-slip relationship of reinforcing bar embedded in concrete. Eng Struct 194:11-25. https://doi.org/10.1016/j.engstruct.2019.05.053

75. Baktheer A, Camps B, Hegger J, Chudoba R (2018) Numerical and experimental investigations of concrete fatigue behaviour exposed to varying loading ranges. In: fib congress. Melbourne, 2018, pp 1110-1123. ISBN: 978-1877040-15-3

76. Baktheer A, Chudoba R (2019) Classification and evaluation of phenomenological numerical models for concrete fatigue behavior under compression. Constr Build Mater 221:661-677. https://doi.org/10.1016/j.conbuildmat.2019. 06.022

77. Alliche A (2004) Damage model for fatigue loading of concrete. Int J Fatigue 26(9):915-921. https://doi.org/10. 1016/j.ijfatigue.2004.02.006

Publisher's Note Springer Nature remains neutral with regard to jurisdictional claims in published maps and institutional affiliations. 